This is the peer reviewed version of the following article:

Mickoleit, F., \& Schüler, D. (2018). Generation of multifunctional magnetic nanoparticles with amplified catalytic activities by genetic expression of enzyme arrays on bacterial magnetosomes. Advanced Biosystems, 2(1), 1700109,

which has been published in final form at https://doi.org/10.1002/adbi.201700109. This article may be used for non-commercial purposes in accordance with Wiley Terms and Conditions for Use of Self-Archived Versions. 


\title{
Generation of Multifunctional Magnetic Nanoparticles with Amplified Catalytic Activities by Genetic Expression of Enzyme Arrays on Bacterial Magnetosomes
}

\author{
Frank Mickoleit, and Dirk Schüler*
}

Dr. F. Mickoleit, Prof. Dr. D. Schüler

University of Bayreuth, Dept. Microbiology, Universitätsstraße 30, 95447 Bayreuth, Germany

E-mail: Dirk.Schueler@uni-bayreuth.de

Keywords: bacterial nanoparticles, magnetosome expression, surface functionalization, glucuronidase, enzyme kinetics

\begin{abstract}
Owing to their highly regulated biosynthesis, magnetosomes biomineralized by magnetotactic bacteria represent natural magnetic nanoparticles with unique physical and chemical properties. They consist of a magnetite core that is surrounded by a biological membrane, and are therefore reminiscent to magnetic "core-shell" nanoparticles. Their usability in many nanotechnological and biomedical applications would be further improved by the introduction of additional catalytic and imaging modalities.
\end{abstract}

Here, a new in vivo strategy is explored for magnetosome display of foreign polypeptides with maximized protein-to-particle ratios. Arrays of up to five monomers of the model enzyme glucuronidase GusA plus the additional fluorophore mEGFP are genetically fused as single large hybrid proteins to highly expressed magnetosome protein anchors. In total, about 190 GusA monomers are covalently attached to individual particles. Assuming layers of GusA rows surrounding the particles, the monomers would thus cover up to $90 \%$ of the magnetosome surface. Our approach generates nanoparticles that exhibit magnetism, fluorescence and stable catalytic activities, which were step-wise increased with the number of GusA monomers. In summary, multicopy expression of arrayed foreign proteins represents a powerful methodology for the biosynthesis of tailored biohybrid magnetic nanoparticles with several genetically encoded and tunable functionalities. 


\section{Introduction}

Magnetosomes are natural magnetic nanoparticles (MNPs) biomineralized by magnetotactic bacteria, in which they serve as geomagnetic field sensor. ${ }^{[1-3]}$ In the alphaproteobacterium Magnetospirillum gryphiswaldense, they consist of a monocrystalline magnetite $\left(\mathrm{Fe}_{3} \mathrm{O}_{4}\right)$ crystal of about $30 \mathrm{~nm}$ in diameter, enveloped by a biological membrane (5-6 $\mathrm{nm}$ in thickness), and are therefore reminiscent to physical core-shell nanoparticles. This so-called magnetosome membrane consists of phospholipids and a set of magnetosome-specific, membrane-associated proteins. ${ }^{[1-5]}$ Due to their highly regulated biosynthesis, ${ }^{[6,7]}$ they represent nanoparticles with unique properties, such as high chemical purity and crystallinity, strong magnetization as well as precise morphologies and uniform sizes, which makes them superior compared to abiogenic MNPs. ${ }^{[8,9]}$ Since these unprecedented features can also be engineered by genetic means, magnetosomes are highly attractive for a number of biotechnological and biomedical uses, such as nanocarriers for magnetic drug targeting, ${ }^{[10]}$ for magnetic capturing of soluble analytes, ${ }^{[9,11]}$ magnetosome-based immunoassays, ${ }^{[12,13]}$ magnetic hyperthermia, ${ }^{[14,15]}$ and as reporters for magnetic resonance imaging $(\mathrm{MRI})^{[16-19]}$ and magnetic particle imaging (MPI). ${ }^{[20,21]}$

However, many applications require the addition of functional moieties to the particle surface. Chemical coupling has been used to functionalize isolated magnetosomes in vitro, ${ }^{[22-24]}$ but lacks selectivity and often requires harsh denaturating conditions. By contrast, genetic approaches are highly selective and allow the manipulation of bacterial magnetosomes in vivo. Foreign proteins were expressed on the particle surface using the magnetosome membrane (Mam) protein MamC (= Mms13) as anchor. Although MamC has only a minor and non-essential function in magnetite biomineralization, ${ }^{[25,26]}$ it is one of the most abundant magnetosome proteins. ${ }^{[27,28]}$ The relatively small $(12.5-\mathrm{kDa})$ protein has two predicted transmembrane helices, an exposed hydrophilic Nterminus and is tightly associated with the magnetosome membrane, ${ }^{[25,27,29]}$ thereby providing covalent attachment of foreign proteins to the magnetosome membrane by translational fusion. ${ }^{[28,30]}$ 
Previous approaches used MamC as anchor for the magnetosomal expression of fluorophores $(\mathrm{GFP})^{[30,31]}$ or camelid antibody fragments (nanobodies), which were for instance used as an intracellular nanotrap and thus, to redirect proteins and even entire organelles within the cells. ${ }^{[32]}$ Furthermore, it was demonstrated that nanobodies can be used for immunoprecipitation of antigentagged proteins. ${ }^{[11]}$ MamC was also exploited for the magnetosomal display of immunoglobulin Gbinding domains, ${ }^{[33]}$ single chain MHCI/peptide complexes ${ }^{[34]}$ and enzyme proteins. For instance, the expression of luciferase as fusion to MamC in M. magneticum resulted in luminescence intensities up to 1,000 times higher than when anchored by Mms16 or MagA, which previously were used as anchor molecules. ${ }^{[33]}$ Further examples of enzyme proteins include the multi-subunit chimeric bacterial RNase P enzyme, which demonstrated that magnetosomes can be employed as scaffolds for the display of multisubunit complexes, ${ }^{[35]}$ and the paraoxonase Opd. ${ }^{[36]}$ However, it still remains unexplored how the activity and stability of enzymes is affected by their magnetosome expression. In addition, potential application (e.g. as magnetic sensors or as bi-/multimodal contrast agents) and functionalization of magnetosomes rely on densely decorated, catalytically active particles with maximized protein-to-particle ratios, which has been difficult to achieve by genetic means. Previous studies attempted to increase magnetosome expression by enhancing the transcription and translation of genetic fusions. For instance, Borg and co-workers ${ }^{[28]}$ developed an improved expression cassette by optimizing the native $\mathrm{P}_{\text {mamDC }}$ promoter and the ribosome binding site (RBS) of the mamC gene. In combination with codon-optimization of the reporter eGFP for magnetobacterial expression (= mEGFP) this led to 2.8 -fold increased expression levels. However, expression could not be further increased by this strategy, as the maximum copy number of MamC anchors within the magnetosome membrane cannot be increased infinitely. In the same study, Borg et al. ${ }^{[28]}$ showed on the other hand that the genetic duplication of the eGFP protein fused in tandem to MamC resulted in enhanced and stable magnetosome fluorescence and an overall increased expression of the eGFP protein. 
In this study, we explored the potential of this strategy by the magnetosome expression of multiple copies of the enzyme protein GusA ( $\beta$-glucuronidase from Escherichia coli) as a model, which in M. gryphiswaldense was previously used as transcriptional reporter to study promoter activities and gene regulation. ${ }^{[28,37,38]}$ We demonstrate that arrays genetically stitched together of up to five GusA monomers plus an additional mEGFP can be fused as a large hybrid protein to a single MamC anchor protein. Purified magnetosome particles exhibited mEGFP fluorescence and a stable, up to 2.8-fold increased specific activity compared to monomeric GusA protein expressed as single-copy magnetosome fusions. Furthermore, catalytic activities were almost linear, sequentially increased with the number of GusA monomers per array. This demonstrates that genetic multiplication is a very powerful strategy for high-level magnetosome expression of foreign proteins and can be used for the biosynthesis of biohybrid nanoparticles with multiple genetically encoded and tunable functionalities.

\section{Results}

\subsection{Magnetosomal expression of GusA-mEGFP fusions results in magnetic fluorescent} particles with stable catalytic activity

Translational fusions of GusA and GusA-mEGFP to MamC were designed as $\operatorname{mamC}-(g u s A)_{n}-m e g f p$ constructs under control of the constitutive, optimized $\mathrm{P}_{\text {mamDC45 }}$ promotor and the optimized ribosome binding site (oRBS). ${ }^{[28]}$ Codon-optimized mEGFP was added as a functional fluorophore and to serve as translational reporter. Variable copy numbers ( $n$ between one and five) of the gusA gene resulted in fusion proteins of different sizes (Figure 1).

First, we investigated single copy expression of GusA in strains WT::mamC-gusA-megfp and the isogenic $\Delta m a m C:: m a m C$-gusA-megfp. mamC-gusA-megfp cassettes were inserted via Tn5 transposition at random chromosomal positions. Selected insertants were undistinguishable from each other with respect to GusA expression, and to wild type cells with respect to growth and cell 
morphology (Figure 2A). mEGFP fluorescence signals were observed at midcell, reflecting the position of the magnetosome chain (Figure 2A, insets). SDS-PAGE and quantitative Western blotting employing anti-GusA antibodies (Figure 2C and Figure S1 in the Supporting Information, SI) confirmed the specific presence of GusA in the purified magnetosome fraction upon cell disruption (harboring $>90 \%$ of the total GusA amount, while only minor quantities were detected in the cytoplasm and the cytoplasmic membrane fraction; data not shown).

As expected, in magnetosomes purified from the complemented deletion strain $\triangle m a m C:: m a m C$ gusA-megfp (which lacks the respective wild type mamC allele) both fluorescence intensities and GusA protein amounts were nearly twice as high as for the corresponding wild type strain (WT::mamC-gusA-megfp: 52 ng GusA/ $\mu \mathrm{g}$ Fe; $\Delta$ mamC::mamC-gusA-megfp: 89 ng GusA / $\mu \mathrm{g}$ Fe; Table 1), probably due to the presence of the unfused MamC copy competing with MamC-GusAmEGFP for magnetosome insertion. GusA amounts were similar to MamC-GusA fusion constructs without mEGFP (WT::mamC-gusA: 58 ng GusA / $\mu$ g Fe, $\Delta m a m C:: m a m C$-gusA: 88 ng GusA / $\mu \mathrm{g}$ $\mathrm{Fe}$ ), indicating that the C-terminal fusion of mEGFP did not affect the expression of GusA. To verify whether magnetosome immobilization of GusA interferes with the catalytic activity and / or the accessibility of the substrate, isolated magnetosomes from strains WT::mamC-gusA, $\Delta m a m C:$ :mamC-gusA, WT::mamC-gusA-megfp and $\triangle m a m C:: m a m C$-gusA-megfp were subjected to GusA activity assays. GusA is a cofactor-independent acid hydrolase that catalyzes the cleavage of 3-glucuronides, yielding 3-glucuronates and an alcohol. The enzyme is very stable and is easily and sensitively assayed using commercially available substrates. ${ }^{[39]}$ In the assay, the time-dependent production of $p$-nitrophenol (generated by the cleavage of $p$-nitrophenyl- $\beta$-D-glucuronide) was monitored. For each fusion $\mathrm{K}_{\mathrm{M}}$ and $\mathrm{v}_{\max }$ values were calculated as the mean of Michaelis-Menten, Lineweaver-Burk and Hanes-Woolf approximations (Table 1 and Figure S2; SI). Magnetosome particles of all fusions exhibited GusA activity (Figure 2B,C), whereas in the cytoplasm and cytoplasmic membrane only minor activities were detectable (shown for $\triangle m a m C:: m a m C$-gusAmegfp in Figure S3; SI). Calculated reaction rates, which are indicators for the amount of 
catalytically active enzyme, correlated well with the amounts of GusA on the particle surface estimated by quantitative Western blots. Specific activities per mg GusA protein of all fusions were within the same range (15.1 - $16.3 \mathrm{U} / \mathrm{mg}$ GusA), and even slightly increased compared to soluble GusA expressed in the cytoplasm (12.7 U / mg GusA) (Table 1). Specific activities per mg Fe were consistent with the enzyme amounts on the particle surface (WT::mamC-gusA-megfp:

$0.79 \mathrm{U} / \mathrm{mg}$ Fe; $\Delta m a m C:: m a m C$-gusA-megfp: $1.45 \mathrm{U} / \mathrm{mg} \mathrm{Fe})$. The different GusA fusions also exhibited comparable $\mathrm{K}_{\mathrm{M}}$ constants $(0.17-0.18 \mathrm{mM})$ indicating similar substrate affinities. Compared to the soluble enzyme expressed in the cytoplasm, $\mathrm{K}_{\mathrm{M}}$ values $(0.28 \mathrm{mM})$ were decreased for all fusions. These data point to a high affinity for $p$-nitrophenyl- $\beta$-D-glucuronide and were in the same range as described before $\left(\mathrm{K}_{\mathrm{M}}=0.13-2.9 \mathrm{mM}\right),{ }^{[40,41]}$ indicating proper folding of the GusA protein.

The enzymatic stability of functionalized MamC-GusA-mEGFP magnetosomes was investigated by subjecting them to multiple cycles of collection and re-addition of fresh substrate. MamC-GusAmEGFP magnetosomes (isolated from strain WT::mamC-gusA-megfp) showed nearly identical catalytic activities and fluorescence after up to ten recollections by centrifugation or magnetic separation (Figure 3 and Figure S4; SI). In addition, MamC-GusA-mEGFP magnetosomes retained 60 and $28 \%$ activity after three and five cycles of freezing and thawing, respectively (Table S1; SI). However, $\mathrm{K}_{\mathrm{M}}$ values increased with the number of cycles, indicating gradual loss of activity, probably due to increasing denaturation of the protein by freeze-thawing.

\subsection{Multicopy-expression of GusA arrays on magnetosomes multiplies enzymatic activity}

Next, we investigated whether enzymatic activities of magnetosomes can be further amplified by expression of multiple GusA copies as arrays. To this end, a set of strains was engineered displaying multiple (up to five) GusA monomers and mEGFP as an additional reporter, fused as single hybrid-proteins to the same MamC magnetosome anchor and connected to each other by Gly 10 linkers (Figure 1). Fusions with multiple GusA copies were expressed in RecA-deficient 
strain M. gryphiswaldense IK-1 to avoid homologous recombination between identical

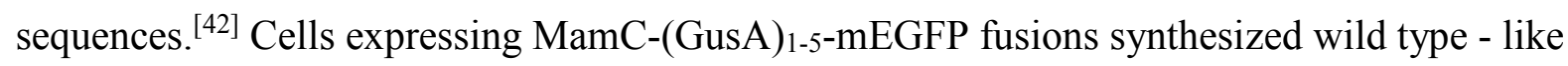
magnetosome chains, with particles arranged ad midcell following a straight line. For strain WT::mamC-gusA-megfp the magnetic response $\left(\mathrm{C}_{\text {mag }}\right.$; i.e. the ratio of light scattering intensities at different angles of magnetic field relative to the light beam, used to characterize the average magnetic orientation of the cells) was comparable to the values obtained for the wild type. $\mathrm{C}_{\mathrm{mag}}$ values for strains derived from IK-1 were consistently slightly lower than those of the wild type due to the somewhat distinct cell morphology of the parental strain as reported earlier. ${ }^{[42]}$ Expression of multiple GusA copies caused an increase of the overall particle diameters of isolated magnetosomes (Figure 4 and Table 2). Zetasizer measurements revealed particle sizes ranging from $47.1 \pm 6.2 \mathrm{~nm}$ (for the WT::mamC-gusA-megfp fusion) to $60.8 \pm 6.7 \mathrm{~nm}$ (for $\Delta r e c A:: m a m C$ -

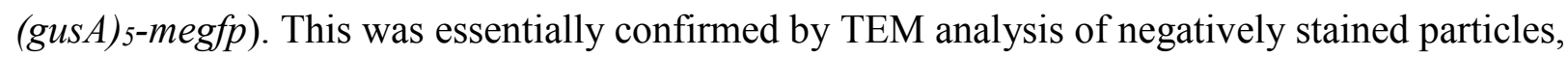
which revealed increased diameters ranging from $39.3 \pm 5.8 \mathrm{~nm}$ for strain $\mathrm{WT}:: m a m C-g u s A-m e g f p$ to $50.5 \pm 8.5 \mathrm{~nm}$ for strain $\Delta r e c A:: m a m C-(g u s A)_{5}-m e g f p$. Wild type particles without fusions were enveloped by an electron-light layer of $5.1 \pm 2.3 \mathrm{~nm}$, likely identical with the native magnetosome membrane. Expression of higher GusA copy numbers led to an increase of this layer up to $10.9 \pm 4.0 \mathrm{~nm}\left(\Delta r e c A:: m a m C\right.$-(gusA) ${ }_{5}$-megfp fusion). TEM analysis also showed an increased spacing between purified magnetosome particles, and electron-light junctions of up to $30 \mathrm{~nm}$ were occasionally observed between isolated MamC-(GusA)2-5-eGFP magnetosomes (Figure 4). The presence of extra organic material is likely due to the (GusA) $)_{n}-m E G F P$ protein arrays at the perimeter of magnetosomes.

In quantitative Western blots electrophoretic mobilities and estimated quantities of fusion proteins correlated well with the predicted GusA copy numbers and masses of hybrid proteins (up to $384.5 \mathrm{kDa}$ for the $5 \mathrm{x}$ fusion). For arrays of up to three GusA copies reaction rates also correlated with the estimated protein amounts (Figure 5 and Table 3). When expressed as arrays of four or even five copies, reaction rates were still further increased (Table 3), with the $\triangle \operatorname{rec} A:: m a m C$ - 
(gusA) ${ }_{5}$-megfp fusion exhibiting the highest particle-bound specific activity $(2.25 \mathrm{U} / \mathrm{mg} \mathrm{Fe})$.

However, beyond the triple fusion increase of activity was no longer linearly proportional to the amount of GusA protein (Figure 5B), and for arrays with four or five GusA monomers also fluorescence (RFU) values were slightly decreased (Figure S4; SI).

\section{Discussion}

Genetic immobilization of single copies of GusA to other microbial structures has been reported earlier. For example, Potot and co-workers ${ }^{[43]}$ displayed GusA monomers on spores of Bacillus subtilis by fusing it to the coat-associated oxalate decarboxylase $\mathrm{OxdD}$, resulting in about $40 \%$ of the GusA spores exhibiting catalytic activity. Sheppard et al. (2011) observed a high activity for GusA when immobilized to living diatom silica by genetic fusion to silaffin protein, resulting in about $0.1 \%(\mathrm{w} / \mathrm{w})$ enzyme loading of the silica. ${ }^{[4]}$ In our study, chromosomal insertion of fusions with multiple copies of GusA in M. gryphiswaldense led to up to $18 \%(\mathrm{w} / \mathrm{w})$ enzyme loading of the magnetosomes and a nearly 3 -fold increased catalytic activity (relative to single copy expression) using genetic multiplication of GusA monomers fused as large hybrid proteins to abundant MamC anchors.

Neither the tethering of GusA arrays to the magnetosome surface nor their covalent linkage by the C-terminus to an additional mEGFP monomer did interfere with the catalytic activity of GusA, indicating proper folding of the fused GusA monomers. Since the GusA enzyme is likely to function as a $272-\mathrm{kDa}$ homotetramer, ${ }^{[41,45,46]}$ the catalytic activity of these fusions depends on the proper folding of the fused GusA monomers and their assembly into GusA tetramers. Monomers from the same multi-GusA protein, and / or monomers from adjacent MamC-(GusA) $)_{n}-m E G F P$ arrays might together contribute to the formation of tetrameric GusA, leading to a highly interconnected GusA 'network' visible as an extra organic electron-light layer attached to the surface of isolated magnetosomes (Figure 4). Due to an increased proximity of single GusA monomers, tetramer formation might be even facilitated, as suggested by decreased $\mathrm{K}_{\mathrm{M}}$ values for 
magnetosomal GusA compared to soluble expressed monomers. However, when expressed in higher numbers ( $>$ three copies), substrate affinity and specific activity decreased (Table 3 ). This might be explained by misassembly of GusA monomers and / or to gradually increasing amounts of misfolded protein units by steric hindrances caused by the high protein content on the surface of MamC-(GusA)4-5-mEGFP magnetosomes. Also, the access of the substrate might become gradually limited within the dense network of multi-GusA arrays. In contrast, poor transcription and translation of the artificially long CDS's (up to $10.4 \mathrm{~kb}$ in length and encoding hybrid proteins of up to $384.5 \mathrm{kDa}$ ) are less likely explanations as suggested by the integrity and expression / abundance of the MamC-(GusA) $)_{n}-m E G F P$ constructs in quantitative Western blots (Figure 5A). The expression of protein arrays substantially increased the amounts of foreign proteins that can be displayed on the surface per single magnetosome particle. For instance, for particles of the strain expressing MamC-(GusA) $)_{5}$-mEGFP, an amount of $225 \mathrm{ng}$ GusA protein per $\mu \mathrm{g}$ Fe was estimated (Table 3), corresponding to $163 \mathrm{ng}$ GusA per $\mu \mathrm{g}$ magnetite. Assuming a size of the magnetite crystal of about $36 \mathrm{~nm}$, a roughly spherical shape, a density of $5.24 \mathrm{~g} \mathrm{~cm}^{-3}$ for magnetite and a mass of $1.33 \times 10^{-16} \mathrm{~g}$, this would relate to a volume of $2.761 \times 10^{-17} \mathrm{~cm}^{3}$, and a surface area of $4,160 \mathrm{~nm}^{2}$. We thus can estimate a number of about 190 GusA monomers per particle. The thickness of the organic layer (Figure 4 and Table 2) and catalytic activities (Figure 5 and Table 3) suggest a rather network-like arrangement of GusA arrays, with all five monomers of the row sticking side onto the surface. Assuming a diameter of about $50 \AA$ for a single monomer, ${ }^{[41,45,46]}$ GusA would cover $3,730 \mathrm{~nm}^{2}$ of the magnetosomes surface, which would be equivalent to a coverage of about $90 \%$. However, due to the described network-like organization of GusA arrays, the actual surface coverage might be lower. In comparison, for the GusA single copy fusion WT::mamC-gusA-megfp 44 GusA monomers were estimated per particle, with a surface coverage

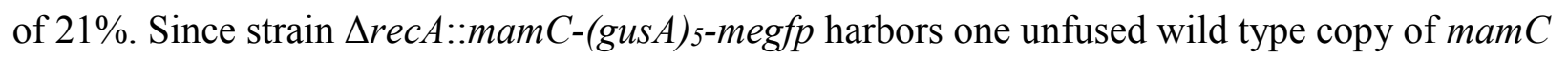
and one additional $m a m C$-(gusA) $)_{5-m e g f p}$ fusion (most likely equally abundant) the number of MamC copies can be calculated to about 80 , which is in accordance with the copy number 
calculated for strain WT::mamC-gusA-egfp (about 85 copies), and with the values reported earlier by Borg and co-workers ( 80 to 250 MamC copies per particle occupying $6-20 \%$ of the magnetosome surface). ${ }^{[28]}$

Future biomedical and biotechnological applications would benefit from (multi-)functionalized magnetic particles with high protein-to-particle-ratios. Since the number of MamC membrane anchors on the magnetosome surface is limited, the simultaneous utilization of further, highly abundant magnetosome membrane proteins could offer a promising way for multi-functionalization approaches. In addition, many applications would require high amounts of functionalized particles, which was hampered by low yields derived from magnetic bacteria. However, recent progress in improving cultivation conditions and genetic engineering of magnetosome biosynthesis has led to considerably increased magnetosome yields and will enable mass production of functionalized magnetosomes. For instance, Zhang and co-workers ${ }^{[47]}$ reported high-density cultivation of M. gryphiswaldense in a large-scale fermentor. Furthermore, the overexpression of magnetosome biosynthesis genes by genomic multiplication in M. gryphiswaldense led to nearly 3-fold increased overproduction of magnetosomes. ${ }^{[48]}$ In addition, Kolinko et al. (2014) succeeded in the transfer of bacterial magnetosome gene clusters to the non-magnetic phototrophic Rhodospirillum rubrum, ${ }^{[49]}$ which demonstrates that mam genes or whole operons can be transferred to organisms that are easier to cultivate and allow high yield magnetosome production.

\section{Conclusion}

In this study, we have demonstrated that multimeric enzymes can be displayed on magnetosome particles in high copy numbers, thereby multiplying their coverage by 5 and nearly triplicating their specific activity per particle. We describe an improved strategy for the generation of tailored coreshell related nanoparticles with several genetically encoded and tunable functionalities including magnetism, the presence of a biological envelope, fluorescence and catalytic activity. Since the stabile expression of catalytically active enzyme proteins, their immobilization and re-usability are 
still common challenges, ${ }^{[50]}$ this provides a highly promising route also for the display of other enzyme proteins and peptides more relevant for both biotechnological, biomedical and research applications. Magnetic imaging techniques for instance would benefit from multi-modal particles that in addition to their magnetic and fluorescent properties display enzyme moieties, receptors or antibodies on the surface. In addition, the properties of magnetic biosensors and protein arrays for drug screening are based on the efficient immobilization of (enzyme) proteins, and a high degree of control over the immobilization process is required, ${ }^{[51,52]}$ which makes genetically engineered magnetosomes to an attractive platform for the high-level display of foreign proteins.

\section{Experimental Section}

Bacterial strains, plasmids, and cultivation conditions. Bacterial strains and plasmids that were used in this study are listed in Table S2 and S3 in the SI. For cultivation of M. gryphiswaldense strains modified flask standard medium was used, ${ }^{[53]}$ and cells were grown microaerobically at $30{ }^{\circ} \mathrm{C}$ under moderate shaking (120 rpm). Both magnetite formation and fluorophore maturation in mEGFP expressing strains were ensured by applying a headspace-toliquid ratio of approximately 1:4 with air in the headspace. Oxygen concentrations declined from high initial levels in the medium with increasing cell numbers, eventually reaching low dissolved oxygen concentrations, permitting magnetite synthesis. ${ }^{[30]}$ E. coli strains were grown as previously described. ${ }^{[54]}$ For the cultivation of E. coli WM3064 D,L- $\alpha, \varepsilon$-diaminopimelic acid (DAP) was added to lysogeny broth (LB) medium at a final concentration of $1 \mathrm{mM}$. Strains were routinely cultured as previously described. ${ }^{[28]}$ For the cultivation on solid medium $1.5 \%(\mathrm{w} / \mathrm{v})$ agar was added. For strains carrying recombinant plasmids, media were supplemented with $25 \mu \mathrm{g} \mathrm{ml}^{-1}$ kanamycin $(\mathrm{Km})$ for $E$. coli and $5 \mu \mathrm{g} \mathrm{ml}^{-1}$ for M. gryphiswaldense strains.

Molecular and genetic techniques. Oligonucleotides (Table S4; SI) were purchased from Sigma-Aldrich (Steinheim, Germany). Plasmids were constructed by standard recombinant techniques as described in detail below. 
Construction of mamC-gusA(-megfp) fusions. M. gryphiswaldense strains MSR-1 FM1 or MSR-1 FM2 were generated by transferring pSB9 to the wild type or $\triangle m a m C$ strain of M. gryphiswaldense, respectively. mamC-gusA expression cassettes were chromosomally inserted by transposition at random positions. For gusA-megfp fusions (strains MSR-1 FM3 and FM4), first gusA was amplified from pSB9 using primers linker-gusA fwd and gusA-linker rev, thereby generating a gly 10 overhang downstream of gusA. megfp was amplified from pJH1 using primers linker-GFP fwd and GFP rev BamHI, thus creating a complementary gly $y_{10}$ overhang upstream of megfp. Both fragments were subsequently fused via overlap $\mathrm{PCR},{ }^{[55]}$ generating a $g l y_{10}$ linker between gusA and megfp. The fusion was cloned into NcoI and BamHI restrictions sites of pSB9, replacing gusA. The resulting plasmid was designated pFM2 and transferred into the wild type or $\triangle m a m C$ strain of M. gryphiswaldense, generating strains MSR-1 FM3 and FM4. mamC-(gusA)2-5megfp fragments were obtained by multi-fragment ligation approaches (Figure S5; SI).

NdeI / BamHI restriction sites of pFM2 were used for the insertion of the constructs into the vector. For the mamC-(gusA) $)_{2}$-megfp fusion, mamC-gusA was amplified from pSB9 using primers mamC NdeI fwd and gusA KpnI rev. gusA was amplified from pSB9 using primers gusA KpnI fwd / gusA SacI rev, and megfp was amplified from pJH1 using linker GFP fwd SacI and GFP rev BamHI. For the $\operatorname{mamC}$-(gusA)$)_{3}$-megfp construct, an additional gusA fragment was amplified using primers gusA SacI ClaI fwd and gusA NcoI rev, and an megfp fragment using primers linker GFP fwd and GFP rev BamHI. The mamC-(gusA) ${ }_{4}-m e g f p$ fusion was generated by replacing megfp (from mamC(gusA) 3-megfp) against a gusA-megfp fragment, amplified from pFM2. Fragments were ligated utilizing the indicated restrictions sites, thereby creating vectors pFM3 (mamC-(gusA) $\left.{ }_{2}-m e g f p\right)$, pFM4 (mamC-(gusA) $\left.)_{3}-m e g f p\right)$ and pFM5 (mamC-(gusA) $\left.{ }_{4}-m e g f p\right)$. For the mamC-(gusA) ${ }_{5}-m e g f p$ cassette, first a mamC-gusA-gusA fragment was created. Primer combinations mamC NdeI fwd / gusA-linker2 rev and linker2-gusA fwd / gusA KpnI rev were used to generate two fragments with complementary overhangs. Both fragments were fused via overlap PCR and cloned into NdeI / KpnI restriction sites of pFM5, thus replacing mamC-(gusA) ${ }_{4}-m e g f p$ by mamC-(gusA) ${ }_{5}$-megfp and 
creating pFM6. All plasmids were transferred into the $\Delta r e c A$ deletion strain $M$. gryphiswaldense MSR-1 IK-1 via conjugation, generating strains M. gryphiswaldense MSR-1 FM5-8. All constructs were sequenced by Macrogen Europe (Amsterdam, Netherlands). Sequence data were analyzed with Geneious 8.0.5 (Biomatters Ltd) and ApE 2.0.47 (M. Wayne Davis, 2009).

Spectrophotometric determination of glucuronidase activity. Enzymatic activity of GusA ( $\beta$ glucuronidase from E. coli, EC 3.2.1.31) was determined using a modified protocol from Myronovskyi et al. ${ }^{[56]}$ GusA cleaves the artificial substrate $p$-nitrophenyl- $\beta$-D-glucuronide, yielding 3-glucuronate and $p$-nitrophenol. The time-dependent production of $p$-nitrophenol was monitored and absorption slopes were determined for different substrate concentrations. These slopes were subsequently taken to draw Michaelis-Menten saturation plots, Lineweaver-Burk plots and HanesWoolf plots.

$1.0 \mathrm{ml}(0.1-0.3 \mu \mathrm{g} \mathrm{Fe})$ of purified particles in dilution buffer (5 mM DTT, 0.1\% Triton X-100, pH 7.0) was centrifuged and incubated at $37^{\circ} \mathrm{C}$ for $15 \mathrm{~min}$. Finally, 5 - $100 \mu 10.2 \mathrm{M} p$-nitrophenyl- $\beta$ D-glucuronide were added to the magnetosome pellet to start the time-dependent reaction (carried out at $37^{\circ} \mathrm{C}$ ). The production of $p$-nitrophenol was monitored by measuring the optical density at $415 \mathrm{~nm}\left(\mathrm{OD}_{415}\right)$. As a reference, $1.0 \mathrm{ml}$ dilution buffer without magnetosomes was used. Units were micromoles $(\mu \mathrm{mol})$ of product formed per minute at $37^{\circ} \mathrm{C}$. Reported values were averaged from at least three independent measurements.

Determination of iron concentrations. Iron contents of cells and isolated magnetosomes were determined by flame atomic absorption spectroscopy. Magnetosomes or cells (suspensions of equal optical density) were pelleted, resuspended in $0.5 \mathrm{ml} 69 \%$ nitric acid and digested at $98{ }^{\circ} \mathrm{C}$ for $3 \mathrm{~h}$. The measurements were conducted with a Perkin-Elmer Atomic Absorption Spectrometer 1100 B (Überlingen, Germany) using the following conditions: wavelength $248.3 \mathrm{~nm}$, gap width $0.2 \mathrm{~nm}$, lamp current $20 \mathrm{~mA}$.

Analytical methods. Optical density (OD) and magnetic response $\left(\mathrm{C}_{\mathrm{mag}}\right)$ of late exponentially phase cells were measured photometrically at $565 \mathrm{~nm}$ as previously reported. ${ }^{[57]}$ Briefly, for $\mathrm{C}_{\mathrm{mag}}$ 
measurements, cells are aligned parallel to the field lines of a magnetic field, resulting in a change in light scattering. The ratio of scattering intensities at different field angles relative to the light beam is used to characterize the average magnetic orientation of the cells. $\mathrm{C}_{\mathrm{mag}}$ is well correlated with the average number of magnetosomes in magnetic cell populations and thus, can be used for semi-quantitative estimations of magnetosome contents.

Expression of mEGFP fusion proteins in M. gryphiswaldense cells was assayed by fluorescence microscopy (Olympus IX81 microscope equipped with a Hamamatsu Orca AG camera) as described before. ${ }^{[30]}$ Image rescaling and cropping were performed with Corel Photopaint 12.0 and GIMP (GNU Image Manipulation Program) 2.8.10 software.

For TEM of whole cells and isolated magnetosomes, specimens were directly deposited onto carbon-coated copper grids. Magnetosomes were stained with $1 \%$ uranyl acetate. Transmission electron microscopy was performed on a CEM 902A (Zeiss, Oberkochen, Germany) with an acceleration voltage of $80 \mathrm{kV}$. Images were taken with a Gata Erlangshen ES500W CCD camera.

Biochemical methods. Isolation of bacterial magnetosomes from M. gryphiswaldense was performed as previously described. ${ }^{[30,53]}$ Polyacrylamide gels were prepared according to the method of Laemmli. ${ }^{[58]}$ Concentrations of (fusion) proteins were determined using the BCA protein kit (Thermo Scientific), and different amounts of isolated magnetosomes $(0.5-10 \mu \mathrm{g} \mathrm{Fe})$ were loaded onto SDS gels $(12 \% \mathrm{w} / \mathrm{v})$. Magnetosome membrane proteins were separated by electrophoresis and subsequently transferred onto polyvinylidene difluoride (PVDF) membranes (Roth, Germany). For immunological detection membranes were blocked / equilibrated in AP-T buffer $\left(0.1 \mathrm{M}\right.$ Tris; $0.1 \mathrm{M} \mathrm{NaCl} ; 5$ mM MgCl 2 x $6 \mathrm{H}_{2} \mathrm{O} ; 0.05 \%$ (v/v) Tween 20; pH 7.4) for $2 \mathrm{~h}$. Primary rabbit anti-GusA IgG antibody (Antibodies-Online, Aachen, Germany) was added at a $1: 7,500$ ratio and incubated for $2 \mathrm{~h}$ at room temperature. Membranes were subsequently washed 4 times with AP-T buffer for 5 min and incubated with a secondary goat anti-rabbit IgG antibody (1 : 30,000; anti-rabbit IgG with conjugated alkaline phosphatase [Sigma, Germany]) for $1 \mathrm{~h}$. Membranes were again washed 4 times with AP-T buffer for 5 min, and finally 15 min in AP buffer 
(0.1 M Tris; $0.1 \mathrm{M} \mathrm{NaCl} ; 5 \mathrm{mM} \mathrm{MgCl} 2 ; \mathrm{pH} 9.5$ ). For staining / detection, the membrane was transferred to a BCIP / NBT substrate solution and incubated until violet bands appeared. The reaction was stopped with acidified water.

Statistical analysis. Statistical analyses were performed using SigmaPlot 12.0 software. Particle sizes and layer thicknesses were determined by zetasizer measurements (Zetasizer software 7.11, Malvern Instruments Ltd.) or measured by TEM images using the software ImageJ, and single pixel ratios were compared to the scale bar. The distance from the magnetite core to the surface of the organic layer was defined as layer thickness. GusA protein amounts on Western blots were calculated densitometrically using the software ImageJ. Origin v7.0220 software was used for drawing Michaelis-Menten saturation curves, curve fitting and determination of kinetic constants. GusA reaction rates $\left(\mathrm{v}_{\max }\right)$ and Michaelis-Menten constants $\left(\mathrm{K}_{\mathrm{M}}\right)$ were calculated as the mean of Michaelis-Menten, Lineweaver-Burk and Hanes-Woolf approximations. Particle displayed fluorescence and fluorescence of whole cells are given as relative fluorescence units (RFU), normalized to iron content or cell density, respectively. If not otherwise stated, error bars represent standard deviations calculated from at least three independent measurements.

\section{Supporting Information}

Supporting Information is available from the Wiley Online Library or from the author.

\section{Acknowledgments}

We thank S. Borg for providing several expression plasmids, and M. Schlotter for expert technical assistance. This project was funded by DFG SPP grant Schu 1080/15-3 and ERC AdG Syntomagx to D. S.. 


\section{References}

[1] C. Jogler, D. Schüler, Annu. Rev. Microbiol. 2009, 63, 501.

[2] A. Komeili, FEMS Microbiol. Rev. 2012, 36, 232.

[3] R. Uebe, D. Schüler, Nat. Rev. Microbiol. 2016, 14, 621.

[4] C. T. Lefèvre, D. A. Bazylinski, Microbiol. Mol. Biol. Rev. 2013, 77, 497.

[5] M. Pósfai, C. T. Lefèvre, D. Trubitsyn, D. A. Bazylinski, R. B. Frankel, Front. Microbiol. 2013, 4, 344.

[6] S. S. Staniland, B. Ward, A. Harrison, G. van der Laan, N. Telling, Proc. Natl. Acad. Sci. U. S. A. 2007, 104, 19524.

[7] S. S. Staniland, A. E. Rawlings, Biochem. Soc. Trans. 2016, 44, 883.

[8] D. Faivre, D. Schüler, Chem. Rev. 2008, 108, 4875.

[9] C. Sun, J. S. H. Lee, M. Zhang, Adv. Drug Delivery Rev. 2008, 60, 1252.

[10] C. Lang, D. Schüler, D. Faivre, Macromol. Biosci. 2007, 7, 144.

[11] A. Pollithy, T. Romer, C. Lang, F. D. Müller, J. Helma, H. Leonhardt, U. Rothbauer, D. Schüler, Appl. Environ. Microbiol. 2011, 77, 6165.

[12] T. Tanaka, T. Matsunaga, Anal. Chem. 2000, 72, 3518.

[13] T. Tanaka, H. Takeda, F. Ueki, K. Obata, H. Tajima, H. Takeyama, Y. Goda, S. Fujimoto, T. Matsunaga T., J. Biotechnol. 2004, 108, 153.

[14] R. Hergt, S. Dutz, M. Röder, J. Phys. Condens. Matter 2008, 20, 385214.

[15] E. Alphandéry, F. Guyot, I. Chebbi, Int. J. Pharm. 2012, 434, 444.

[16] R. Weissleder, A. Moore, U. Mahmood, R. Bhorade, H. Benveniste, E. A. Chiocca, J. P. Basilion, Nat. Med. 2000, 6, 351.

[17] W. S. Seo, J. H. Lee, X. Sun, Y. Suzuki, D. Mann, Z. Liu, M. Terashima, P. C. Yang, M. V. McConnell, D. G. Nishimura, H. Dai, Nat. Mater. 2006, 5, 971.

[18] J. H. Lee, Y. M. Huh, Y. Jun, J. Seo, J. Jang, H. T. Song, S. Kim, E. J. Cho, H. G. Yoon, J. S. Suh, J. Cheon, Nat. Med. 2007, 13, 95-99. 
[19] R. Taukulis, M. Widdrat, M. Kumari, D. Heinke, M. Rumpler, É. Tompa, R. Uebe, A. Kraupner, A. Cebers, D. Schüler, M. Pósfai, A. Hirt, D. Faivre, MHD 2015, 51, 721.

[20] A. Kraupner et al., presented at International Workshop on Magnetic Particle Imaging, Istanbul, Turkey, 2015. Bacterial magnetosomes are a new type of biogenic MPI tracers: IWMPI 2015.

[21] A. Kraupner, D. Eberbeck, D. Heinke, R. Uebe, D. Schüler, A. Briel, Nanoscale 2017, accepted.

[22] T. Matsunaga, S. Kamiya, Appl. Microbiol. Biotechnol. 1987, 26, 328.

[23] B. Ceyhan, P. Alhorn, C. Lang, D. Schüler, C. M. Niemeyer, SMALL 2006, 2, 1251.

[24] R. Wacker, B. Ceyhan, P. Alhorn, D. Schüler, C. Lang, C. M. Niemeyer, Biochem. Biophys. Res. Commun. 2007, 357, 391.

[25] K. Grünberg, C. Wawer, B. M. Tebo, D. Schüler, Appl. Environ. Microbiol. 2001, 67, 4573.

[26] A. Scheffel, A. Gärdes, K. Grünberg, G. Wanner, D. Schüler, J. Bacteriol. 2008, 190, 377.

[27] K. Grünberg, E. C. Müller, A. Otto, R. Reszka, D. Linder, M. Kube, R. Reinhardt, D. Schüler, Appl. Environ. Microbiol. 2004, 70, 1040.

[28] S. Borg, J. Hofmann, A. Pollithy, C. Lang, D. Schüler, Appl. Environ. Microbiol. 2014, 80, 2609.

[29] H. Nudelman, R. Zarivach, Front. Microbiol. 2014, 5, 9.

[30] C. Lang, D. Schüler, Appl. Environ. Microbiol. 2008, 74, 4944.

[31] C. Lang, D. Schüler, J. Phys.: Condens. Matter 2006, 18, 2815.

[32] S. Borg, F. Popp, J. Hofmann, H. Leonhardt, U. Rothbauer, D. Schüler, MBio. 2015, 6, pii: e02117-14.

[33] T. Yoshino, T. Matsunaga, Appl. Environ. Microbiol. 2006, 72, 465.

[34] T. Honda, Y. Maeda, T. Yasuda, T. Tanaka, T. Matsunaga, T. Yoshino, Protein Eng. Des. Sel. 2015, $28,53$.

[35] S. Ohuchi, D. Schüler, Appl. Environ. Microbiol. 2009, 75, 7734. 
[36] N. Ginet, R. Pardoux, G. Adryanczyk, D. Garcia, C. Brutesco, D. Pignol, PLoS One 2011, 6, e21442. doi: 10.1371/journal.pone.0021442.

[37] Y. Li, E. Katzmann, S. Borg, D. Schüler, J. Bacteriol. 2012, 194, 4847.

[38] Y. Li, M. Sabaty, S. Borg, K. T. Silva, D. Pignol, D. Schüler, BMC Microbiol. 2014, 14,153.

[39] R. A. Jefferson, S. M. Burgess, D. Hirsh, Proc. Natl. Acad. Sci. U. S. A. 1986, 83, 8447.

[40] D. Schomberg, M. Salzmann Ed., Enzyme Handbook Springer-Verlag, 1991.

[41] B. D. Wallace, A. B. Roberts, R. M. Pollet, J. D. Ingle, K. A. Biernat, S. J. Pellock, M. K. Venkatesh, L. Guthrie, S. K. O’Neal, S. J. Robinson, M. Dollinger, E. Figueroa, S. R. McShane, R. D. Cohen, J. Jin, S. V. Frye, W. C. Zamboni, C. Pepe-Ranney, S. Mani, L. Kelly, M. R. Redinbo, Chem. Biol. 2015, 22, 1238.

[42] I. Kolinko, C. Jogler, E. Katzmann, D. Schüler, J. Bacteriol. 2011, 193, 5328.

[43] S. Potot, C. R. Serra, A. O. Henriques, G. Schyns, Appl. Environ. Microbiol. 2010, 76, 5926.

[44] V. C. Sheppard, A. Scheffel, N. Poulsen, N. Kröger, Appl. Environ. Microbiol. 2012, 78, 211.

[45] B. D. Wallace, H. Wang, K. T. Lane, J. E. Scott, J. Orans, J. S. Koo, M. Venkatesh, C. Jobin, L. A. Yeh, S. Mani, M. R. Redinbo, Science 2010, 330, 831.

[46] A. B. Roberts, B. D. Wallace, M. K. Venkatesh, S. Mani, M. R. Redinbo, Mol. Pharmacol. 2013, 84, 208.

[47] Y. Zhang, X. Zhang, W. Jiang, Y. Li, J. Li, Appl. Environ. Microbiol. 2011, 77, 5851.

[48] A. Lohße, I. Kolinko, O. Raschdorf, R. Uebe, S. Borg, A. Brachmann, J. M. Plitzko, R. Müller, Y. Zhang, D. Schüler, Appl. Environ. Microbiol. 2016, 82, 3032.

[49] I. Kolinko, A. Lohße, S. Borg, O. Raschdorf, C. Jogler, Q. Tu, M. Pósfai, E. Tompa, J. M. Plitzko, A. Brachmann, G. Wanner, R. Müller, Y. Zhang, D. Schüler, Nat. Nanotechnol. 2014, 9, 193.

[50] T. Narancic, R. Davis, J. Nikodinovic-Runic, K. E. O’Connor, Biotechnol. Lett. 2015, 37, 943.

[51] J. F. Liang, Y. T. Li, V. C. Yang, J. Pharm. Sci. 2000, 89, 979.

[52] M. Meldal, S. Schoffelen, F1000Research 2016, 5, 2303. 
[53] U. Heyen, D. Schüler, Appl. Microbiol. Biotechnol. 2003, 61, 536.

[54] J. Sambrook, D. Russell, Molecular cloning: a laboratory manual, 3rd ed, p 1-44. Cold Spring Harbor Laboratory Press, New York, NY, 2001.

[55] A. V. Bryksin, I. Matsumura, Biotechniques 2010, 48, 463.

[56] M. Myronovskyi, E. Welle, V. Fedorenko, A. Luzhetskyy, Appl. Environ. Microbiol. 2011, $77,5370$.

[57] D. Schüler, U. Rainer, E. Bäuerlein, FEMS Microbiol. Lett. 1995, 132, 139.

[58] U. K. Laemmli, Nature 1970, 227, 680. 


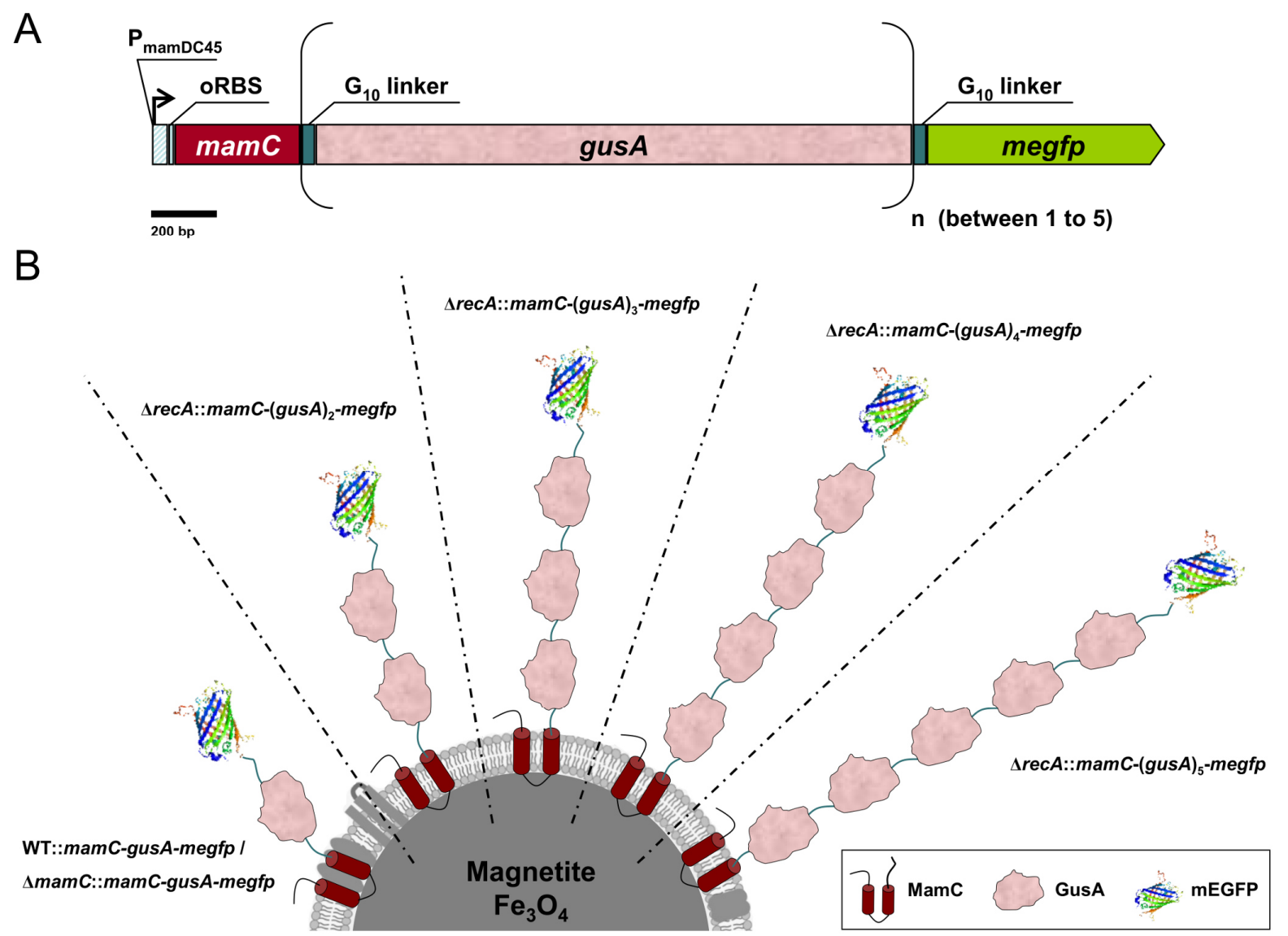

Figure 1. (A) Schematic representation showing the genetic organization of the constructed expression cassettes for the display of MamC-(GusA) $)_{n}$-mEGFP fusions on the magnetosome surface. (B) The resulting particles displayed arrays of one to five copies of GusA and mEGFP as fluorophore and additional translational reporter. MamC, GusA monomers and mEGFP were fused via $\mathrm{G}_{10}$ linkers composed of ten glycine residues. (Size of particles and proteins not to scale) 
A

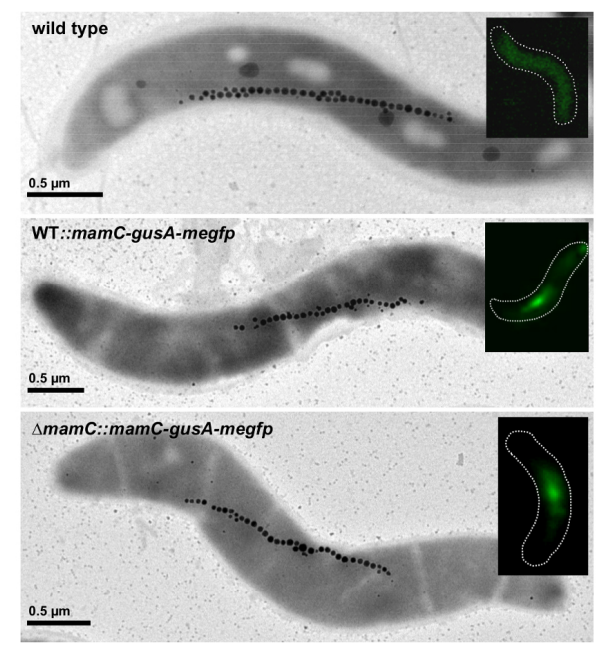

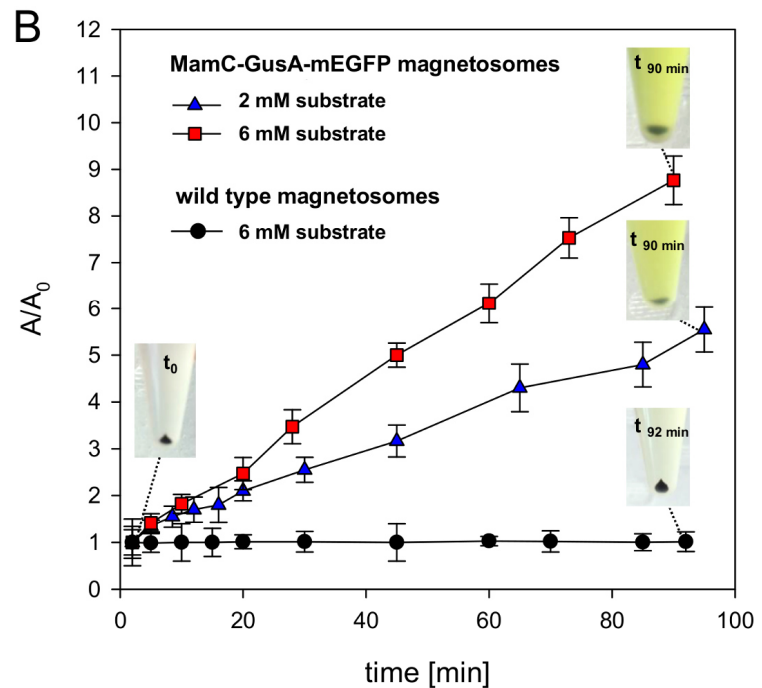

C

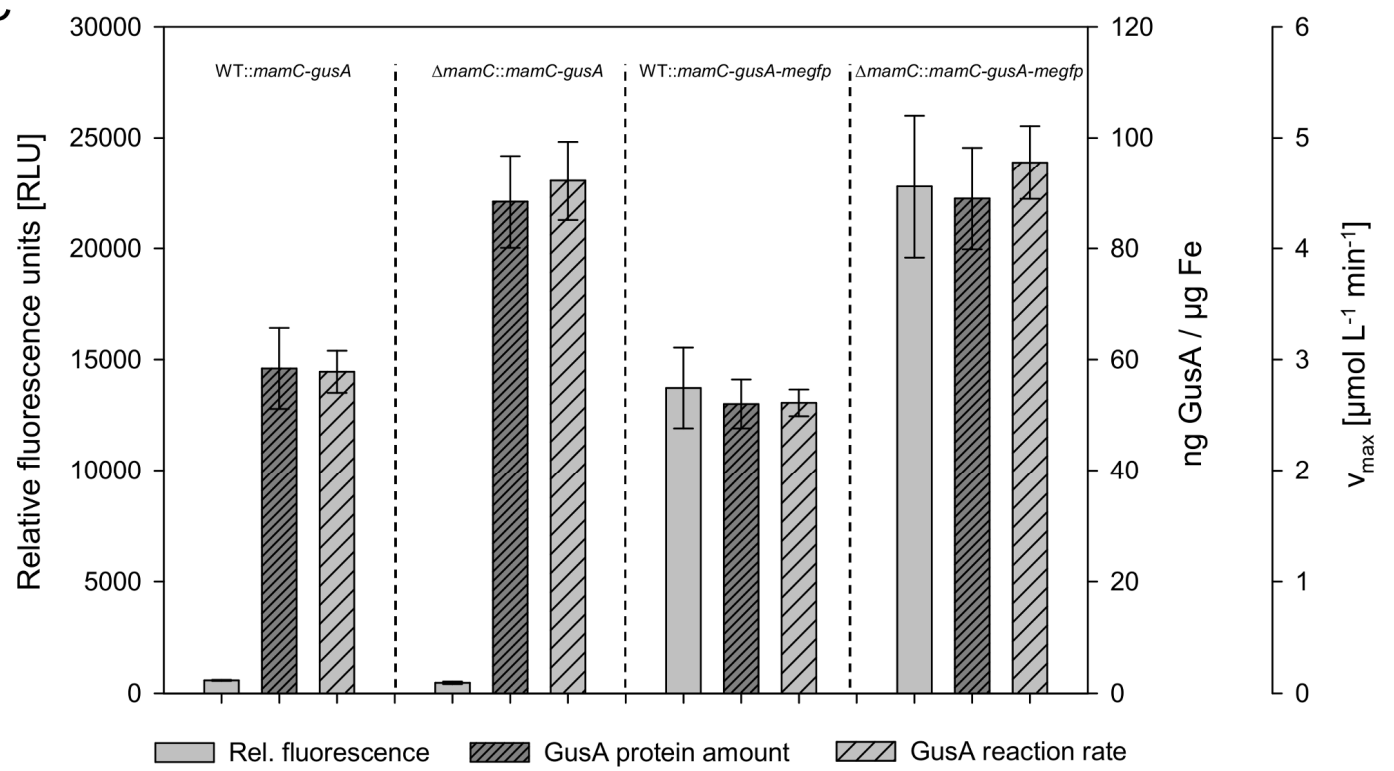

Figure 2. Magnetosome expression of MamC-GusA or MamC-GusA-mEGFP fusions. (A) Transmission electron micrographs of WT::mamC-gusA-megfp and $\Delta$ mamC::mamC-gusA-megfp cells indicate a wild type - like, chain - like arrangement of magnetosomes, positioned at midcell. mEGFP expression was confirmed by fluorescence microscopy (insets), showing fluorescence at magnetosome chain position. (B) Glucuronide-hydrolyzing activity of MamC-GusA-mEGFP magnetosomes. In the assay, $p$-nitrophenol- $\beta$-D-glucuronide was cleaved by GusA, yielding 3glucuronate and $p$-nitrophenol. Formation of the latter was monitored by measuring the absorption increase at $415 \mathrm{~nm}$ and resulted in a characteristic yellow color of the supernatant (insets).

Enzymatic activities were normalized and are given as $\mathrm{A} / \mathrm{A}_{0}$ ratios, with $\mathrm{A}_{0}$ representing the initial activity. (C) Bar chart illustrating cellular mEGFP fluorescence, particle-displayed GusA amounts and GusA reaction rates $\left(\mathrm{v}_{\max }\right)$ of the indicated M. gryphiswaldense strains. Fluorescence was normalized to cell density and reported as relative fluorescence units (RFU). For quantification of GusA on the particle surface, isolated magnetosomes were subjected to denaturing PAGE (1.5 or 3 $\mu \mathrm{g} \mathrm{Fe} /$ lane) followed by quantitative Western blotting employing an IgG antibody directed against GusA. GusA reaction rates $\left(\mathrm{v}_{\max }\right)$ were calculated as the mean of Michaelis-Menten, LineweaverBurk and Hanes-Woolf approximations.

Error bars represent standard deviations calculated from at least three independent measurements. 


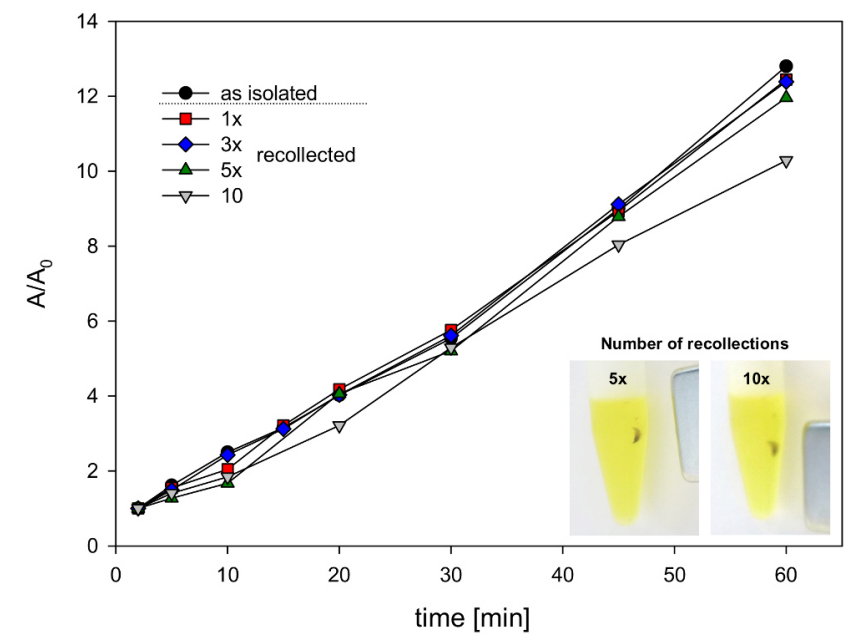

Figure 3. Enzymatic activity of isolated MamC-GusA-mEGFP magnetosomes after several cycles of centrifugation and resuspension. The time-dependent production of $p$-nitrophenol through hydrolysis of the artificial substrate $p$-nitrophenyl- $\beta$-D-glucuronide was monitored, and absorption values were normalized for direct comparison. Insets: Magnetosome pellets exhibiting glucuronidehydrolyzing activity accumulated next to the pole of an external permanent magnet.

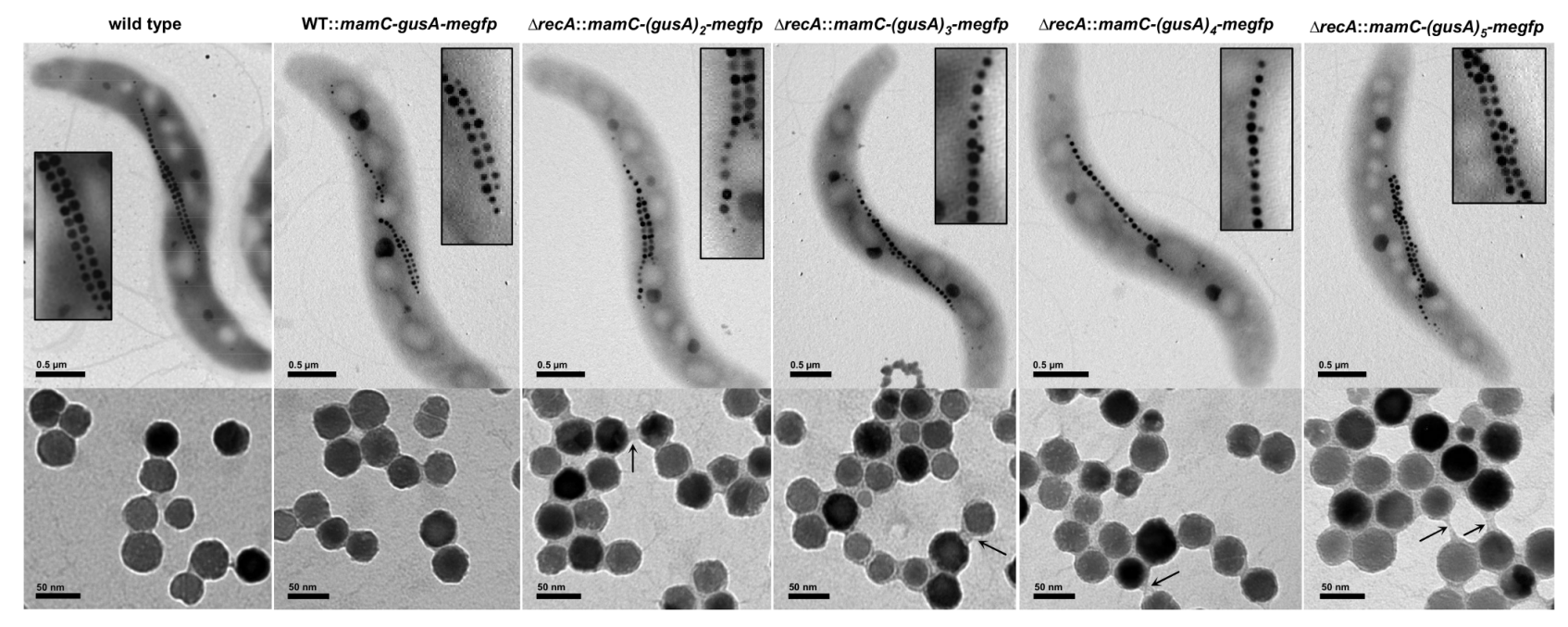

Figure 4. Upper panel: TEM of representative cells of the wild type and the mutant strains mamC(gusA) 1-5-megfp of M. gryphiswaldense. Wild type - like particle arrangement of one or two magnetosome chains positioned at midcell were observed in all strains. Lower panel: TEM of isolated, negatively stained magnetosomes revealed an organic layer of up to $10.9 \pm 4.0 \mathrm{~nm}$ in thickness, thereby increasing the particle diameter and the distances between magnetite cores. Arrows indicate junctions of up to $30 \mathrm{~nm}$ between particles of mamC-(gusA) ${ }_{2-5}-m e g f p$ fusions. 

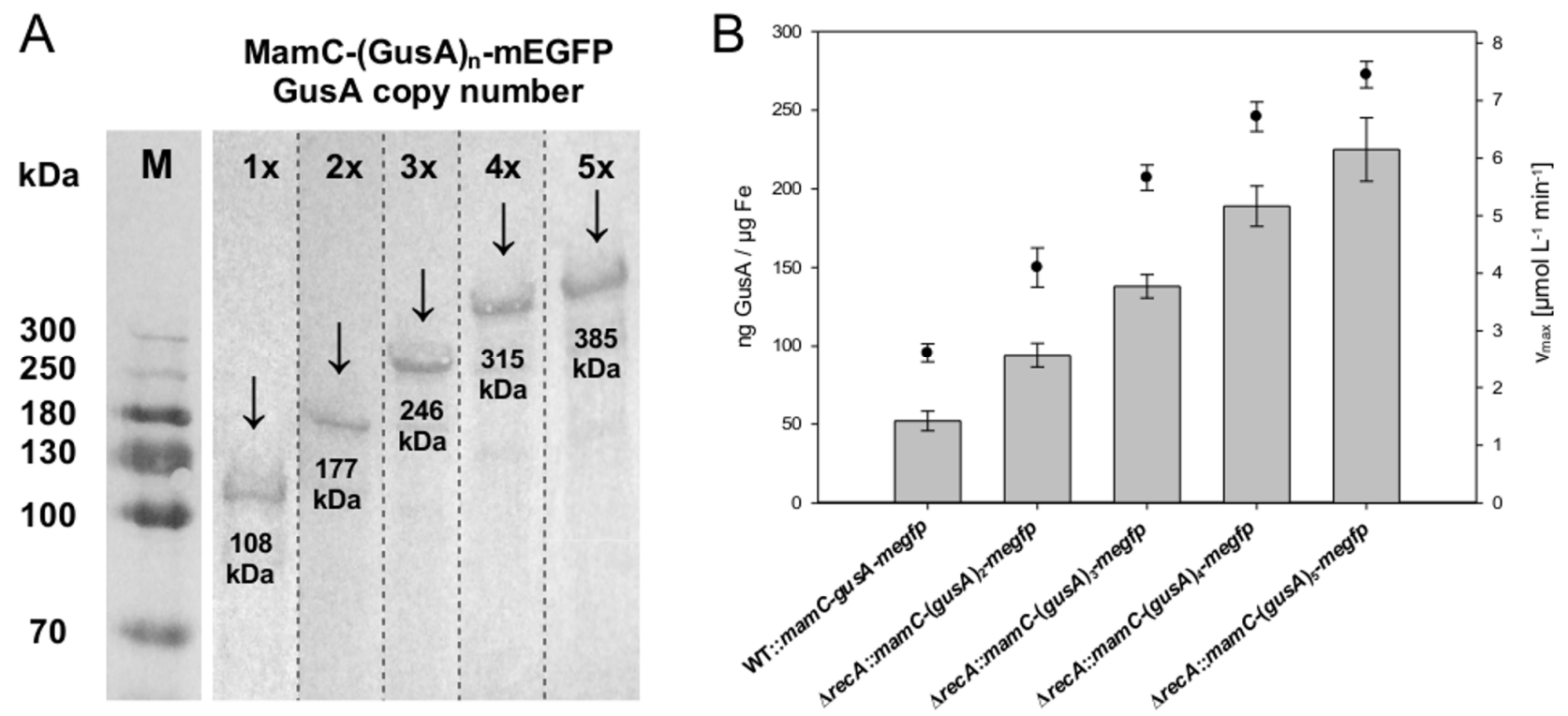

Figure 5. Magnetosome expression and catalytic activity of MamC-(GusA)n-mEGFP arrays with up to five GusA copies. The mamC-gusA-megfp fusion was expressed in the wild type background of M. gryphiswaldense, fusions mamC-(gusA) $2-5-m e g f p$ in the $\Delta r e c A$ background. (A) Magnetosome membrane associated proteins solubilized from isolated particles $(3 \mu \mathrm{g} \mathrm{Fe} /$ lane $)$ of the indicated strains were subjected to denaturing PAGE followed by quantitative Western blotting employing an IgG antibody directed against GusA. GusA copy numbers of MamC-(GusA) $)_{n}-m E G F P$ fusions are indicated as $1 \mathrm{x}-5 \mathrm{x}$, detected bands are indicated with arrows and the predicted molecular masses. $\mathrm{M}$, protein molecular weight marker. (B) Chart illustrating GusA expression and activity on the magnetosome surface. GusA amounts clearly correlated with the enzyme copy number(s). Reaction rates $(\bullet)$ increased with the number of GusA units expressed on the particle surface, however, beyond the triple fusion $(n>3)$ increase of activity was no longer linearly proportional to the amount of GusA protein. Error bars represent standard deviations calculated from at least three independent measurements.

Table 1. GusA activity displayed by different magnetosome species. Magnetosomes were isolated from the indicated M. gryphiswaldense strains and subjected to GusA activity assays $(3.3 \mu \mathrm{g} \mathrm{Fe})$ to determine $\mathrm{K}_{\mathrm{M}}$ and $\mathrm{v}_{\max }$. GusA protein amounts (estimated densitometrically from quantitative Western blots, Figure S1; SI) were used to calculate specific enzymatic activities.

\begin{tabular}{|c|c|c|c|c|c|}
\hline Strain & ng GusA / $\mu \mathrm{g} \mathrm{Fe}$ & $\begin{array}{c}\mathrm{K}_{\mathrm{M}} \\
{[\mathrm{mM}]}\end{array}$ & $\begin{array}{c}\mathrm{V}_{\max } \\
{\left[\mu \mathrm{mol} \mathrm{L} \mathrm{L}^{-1} \mathrm{~min}^{-1}\right]}\end{array}$ & $\begin{array}{l}\text { Spec. activity } \\
\text { [U/mg GusA] }\end{array}$ & $\begin{array}{c}\text { Spec. activity } \\
{[\mathrm{U} / \mathrm{mg} \mathrm{Fe}]}\end{array}$ \\
\hline$\overline{\mathrm{WT}:: m a m C-g u s A}$ & 58 & 0.19 & 2.89 & 15.1 & 0.88 \\
\hline$\Delta m a m C:: m a m C-g u s A$ & 88 & 0.18 & 4.61 & 15.9 & 1.40 \\
\hline WT::mamC-gusA-megfp & 52 & 0.17 & 2.61 & 15.2 & 0.79 \\
\hline$\Delta m a m C:: m a m C-g u s A-m e g f p$ & 89 & 0.18 & 4.78 & 16.3 & 1.45 \\
\hline $\begin{array}{l}\text { soluble (cytoplasmic) GusA } \\
\text { (control) }\end{array}$ & --- & 0.28 & 0.28 & 12.7 & --- \\
\hline
\end{tabular}


Table 2. Particle sizes of magnetosomes isolated from mamC-(gusA) 1-5-megfp mutant strains. Diameters were determined by TEM $(n=200)$ and zetasizer analysis (three independent measurements). Particle suspensions were analyzed in $10 \mathrm{mM}$ Hepes / $1 \mathrm{mM}$ EDTA at pH 7.2.

\begin{tabular}{|c|c|c|c|c|c|c|}
\hline \multirow[t]{2}{*}{ Strain } & \multirow{2}{*}{$\begin{array}{c}\text { GusA copy } \\
\text { number }\end{array}$} & \multicolumn{2}{|c|}{ Overall diameter [nm] } & \multirow{2}{*}{$\begin{array}{c}\text { Diameter } \\
\text { magnetite core } \\
(\text { TEM) }[\mathrm{nm}]\end{array}$} & \multirow{2}{*}{$\begin{array}{c}\text { Thickness of } \\
\text { organic layer } \\
\text { (TEM) }[\mathrm{nm}]\end{array}$} & \multirow{2}{*}{$\begin{array}{c}\text { Magnetic } \\
\text { response } \\
\left(\mathrm{C}_{\mathrm{mag}}\right)\end{array}$} \\
\hline & & zetasizer & TEM & & & \\
\hline wild type & 0 & $40.7 \pm 4.1$ & $38.1 \pm 7.3$ & $35.9 \pm 6.7$ & $5.1 \pm 2.3$ & $1.64 \pm 0.26$ \\
\hline $\begin{array}{l}\text { WT::mamC- } \\
\text { gusA-megfp }\end{array}$ & 1 & $47.1 \pm 6.2$ & $39.3 \pm 5.8$ & $36.3 \pm 5.8$ & $4.8 \pm 2.2$ & $1.57 \pm 0.33$ \\
\hline $\begin{array}{l}\Delta r e c A:: m a m C- \\
(g u s A)_{2}-m e g f p\end{array}$ & 2 & $50.7 \pm 4.9$ & $44.7 \pm 6.3$ & $38.1 \pm 7.2$ & $7.2 \pm 2.4$ & $1.01 \pm 0.32$ \\
\hline $\begin{array}{l}\Delta r e c A:: m a m C- \\
(g u s A)_{3}-m e g f p\end{array}$ & 3 & $55.7 \pm 7.3$ & $49.8 \pm 6.6$ & $43.9 \pm 6.3$ & $10.1 \pm 3.7$ & $0.97 \pm 0.28$ \\
\hline $\begin{array}{l}\Delta r e c A:: m a m C- \\
(g u s A)_{4}-m e g f p\end{array}$ & 4 & $59.8 \pm 5.2$ & $50.4 \pm 4.7$ & $41.8 \pm 6.1$ & $10.4 \pm 3.4$ & $0.99 \pm 0.37$ \\
\hline $\begin{array}{l}\Delta r e c A:: m a m C- \\
(g u s A)_{5}-\text { megfp }\end{array}$ & 5 & $60.8 \pm 6.7$ & $50.5 \pm 8.5$ & $36.4 \pm 4.2$ & $10.9 \pm 4.0$ & $0.95 \pm 0.36$ \\
\hline
\end{tabular}

Table 3. Protein amounts, copy numbers and enzymatic activities of magnetosomes displaying GusA arrays on the particle surface. Denaturing PAGE with subsequent quantitative Western blotting was used to estimate the molecular masses of the fusions according to their electrophoretic mobility. The obtained values are compared with the theoretical masses based on amino acid composition. Furthermore, magnetosomes were subjected to activity assays to determine $\mathrm{K}_{M}$ and $\mathrm{V}_{\max }(3.3 \mu \mathrm{g} \mathrm{Fe}$ ) (Figure S2; SI). GusA protein amounts (calculated by densitometrical analysis of PVDF membranes, Figure 5A) were subsequently used to calculate specific enzymatic activities.

\begin{tabular}{|c|c|c|c|c|c|c|c|c|}
\hline Strain & $\begin{array}{l}\text { Predicted } \\
\text { molecular } \\
\text { mass }[k D a]\end{array}$ & $\begin{array}{c}\text { Estimated } \\
\text { molecular mass } \\
\text { (calculated } \\
\text { according } \\
\text { PAGE) [kDa] }\end{array}$ & $\begin{array}{c}\text { ng GusA / } \\
\mu \mathrm{g} \mathrm{Fe}\end{array}$ & $\begin{array}{c}\text { estimated } \\
\text { GusA copy } \\
\text { number }\end{array}$ & $\begin{array}{c}\mathrm{K}_{\mathrm{M}} \\
{[\mathrm{mM}]}\end{array}$ & $\begin{array}{c}\mathrm{v}_{\max } \\
{\left[\mu \mathrm{mol} \mathrm{L}{ }^{-1} \mathrm{~min}^{-1}\right]}\end{array}$ & $\begin{array}{l}\text { specific } \\
\text { activity } \\
{[\mathrm{U} / \mathrm{mg}} \\
\text { GusA] }\end{array}$ & $\begin{array}{c}\text { specific } \\
\text { activity } \\
{[\mathrm{U} / \mathrm{mg}} \\
\mathrm{Fe}]\end{array}$ \\
\hline $\begin{array}{l}\text { WT::mamC- } \\
\text { gusA-megfp }\end{array}$ & 108.2 & 115.6 & 52 & -- & 0.17 & 2.61 & 15.2 & 0.79 \\
\hline $\begin{array}{l}\Delta r e c A:: m a m C- \\
(g u s A)_{2}-\text { megfp }\end{array}$ & 177.3 & 190.4 & 94 & 1.8 & 0.26 & 4.10 & 13.2 & 1.24 \\
\hline $\begin{array}{l}\Delta r e c A:: m a m C- \\
(g u s A)_{3} \text {-megfp }\end{array}$ & 246.4 & 272.6 & 138 & 2.7 & 0.86 & 5.66 & 12.4 & 1.71 \\
\hline $\begin{array}{l}\Delta r e c A:: m a m C- \\
(g u s A)_{4}-\text { megfp }\end{array}$ & 315.4 & 337.9 & 189 & 3.6 & 0.85 & 6.72 & 10.8 & 2.04 \\
\hline $\begin{array}{l}\Delta r e c A:: m a m C- \\
(g u s A)_{5}-\text { megfp }\end{array}$ & 384.5 & 418.1 & 225 & 4.3 & 1.82 & 7.45 & 10.0 & 2.25 \\
\hline
\end{tabular}


Table of contents entry:

Magnetosomes biomineralized by magnetotactic bacteria represent magnetic nanoparticles with unique physical and chemical properties. Here, a new in vivo strategy is investigated for magnetosome display of foreign polypeptides with maximized protein-to-particle ratios. Multi-copy expression of arrayed foreign proteins generates biohybrid nanoparticles with several genetically encoded functionalities (i.e., magnetism, fluorescence and high catalytic activity).

Keyword: Multifunctional Nanoparticles

Frank Mickoleit, and Dirk Schüler*

Title:

Generation of Multifunctional Magnetic Nanoparticles with Amplified Catalytic Activities by Genetic Expression of Enzyme Arrays on Bacterial Magnetosomes

\section{ToC figure}

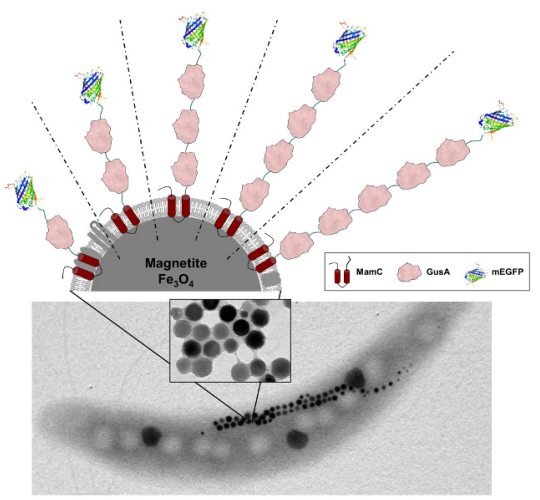




\section{Supporting Information}

Generation of Multifunctional Magnetic Nanoparticles with Amplified Catalytic Activities by Genetic Expression of Enzyme Arrays on Bacterial Magnetosomes

Frank Mickoleit, and Dirk Schüler*

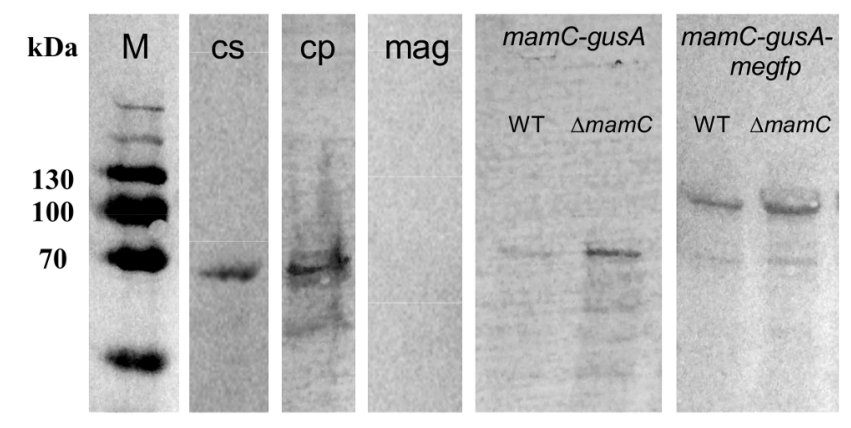

Figure S1. Magnetosome expression of MamC-GusA(-mEGFP) fusion proteins. The wild type (WT) of $M$. gryphiswaldense and the $\triangle \operatorname{mamC}$ deletion strain were complemented with the indicated mamC-gusA or mamC-gusA-megfp fusions. Microoxically grown cells were harvested and disrupted, and the isolated magnetosome fractions ( 1.5 or $3 \mu \mathrm{g} \mathrm{Fe} /$ lane) were subjected to denaturing PAGE followed by quantitative Western blotting employing an IgG antibody directed against GusA. Bands were detected for each fusion, and electrophoretic mobilities corresponded to the calculated molecular masses. Degradation products potentially caused by the sample preparation were detected to only minor extents. The following references were included: cs, control (soluble GusA protein purchased from Sigma Aldrich); cp, cytoplasmic GusA (expressed in the soluble fraction); mag, isolated wild type magnetosomes. 

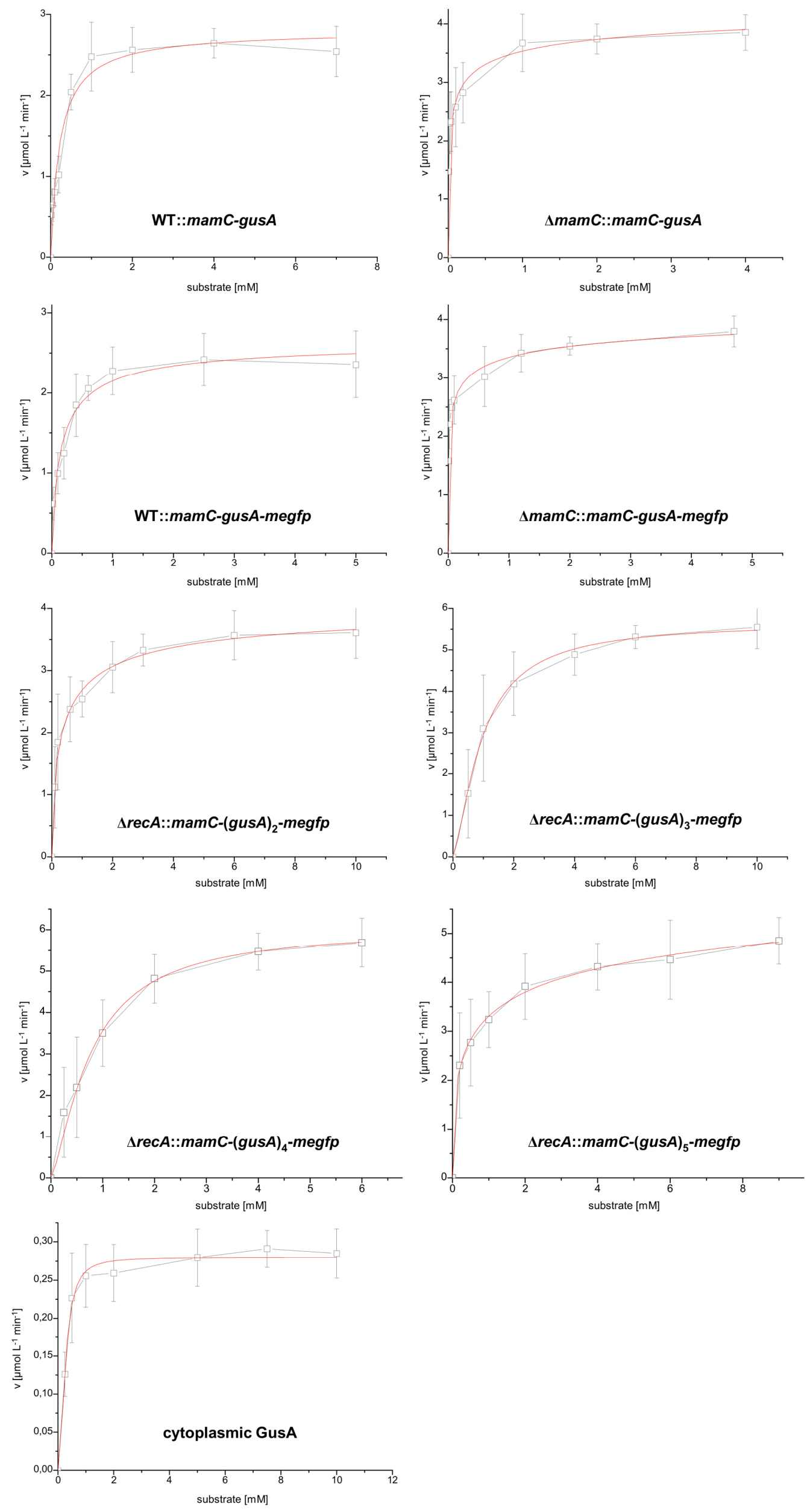
Figure S2. Michaelis-Menten saturation curves showing the relation between the substrate concentration and reaction rate for GusA magnetosomes isolated from the indicated strains of $M$. gryphiswaldense and for the soluble expressed enzyme. GusA activity was determined using a modified protocol from Myronovskyi et al. (2011). GusA cleaves the artificial substrate $p$-nitrophenyl- $\beta$-D-glucuronide, yielding 3-glucuronate and $p$-nitrophenol. The time-dependent production of $p$-nitrophenol was monitored and absorption slopes were determined, which were subsequently taken to calculate reaction rates. Error bars are based on at least three independent determinations. Software Origin v7.0220 (OriginLab Corporation, Northampton, MA, USA) was used for curve fitting and determination of kinetic constants $K_{M}$ and $v_{\max }$.

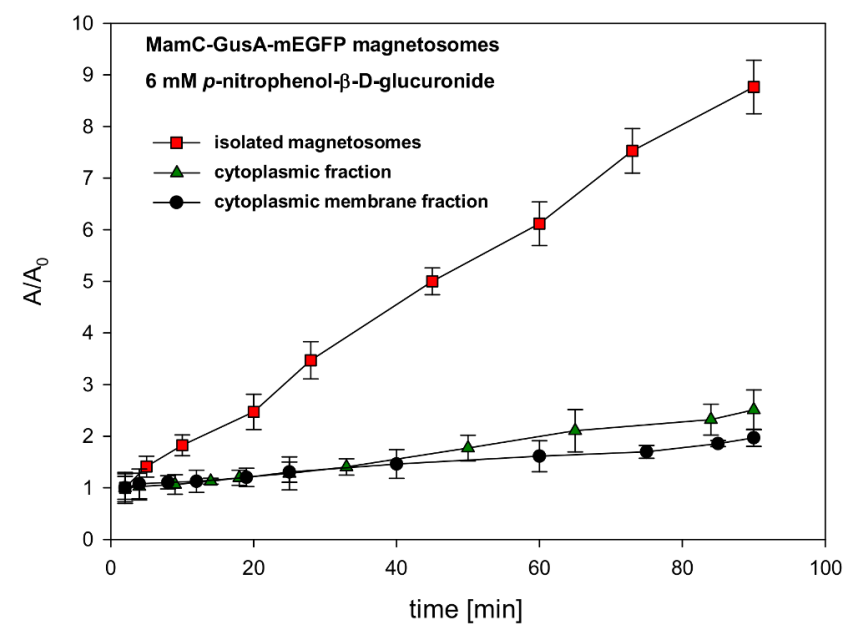

Figure S3. Glucuronide-hydrolyzing activity of different subcellular fractions of strain $\Delta m a m C:: m a m C$-gusA-megfp. In the assay, $p$-nitrophenol- $\beta$-D-glucuronide was cleaved by GusA, yielding 3-glucuronate and $p$-nitrophenol. Formation of the latter was monitored by measuring the absorption increase at $415 \mathrm{~nm}$. Isolated MamC-GusA-mEGFP magnetosomes exhibited significant glucuronide-hydrolyzing activity. For the cytoplasm and cytoplasmic membrane fraction only marginal activities were measured. Error bars represent standard deviations calculated from at least three independent measurements. 


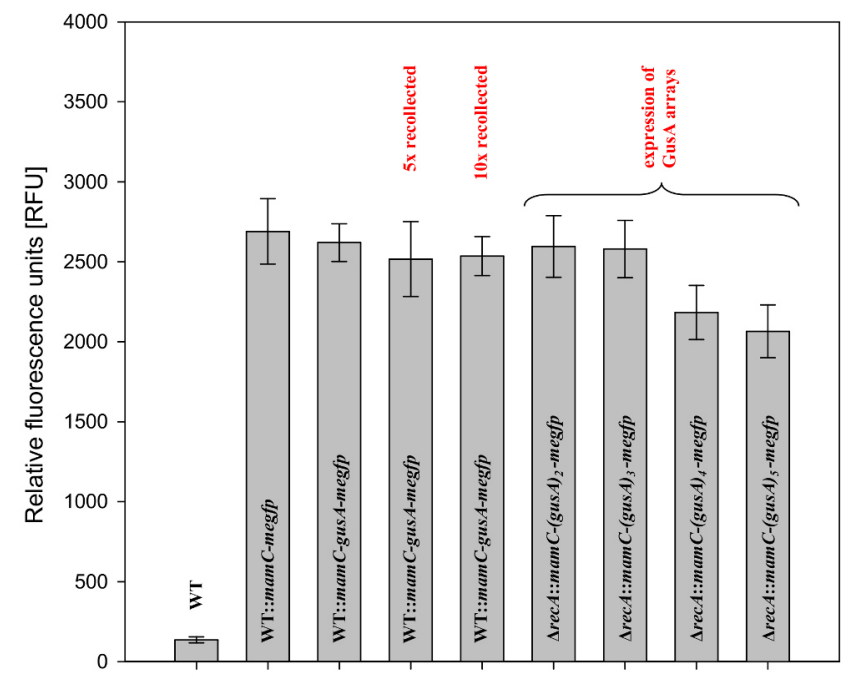

Figure S4. mEGFP fluorescence displayed by magnetosomes isolated from various M. gryphiswaldense strains. Fluorescence was normalized to an iron content of $5 \mu \mathrm{g}$ and reported as relative fluorescence units (RFU). Error bars represent standard deviations, calculated from at least three independent experiments. For wild type particles only a weak background fluorescence was measured, whereas for particles from mutant strains WT::mamC-megfp and WT::mamC-gusAmegfp comparable intensities were obtained, even after 10 cycles of recollection. Magnetosomes displaying (GusA)2-5-mEGFP arrays on the surface exhibited fluorescence intensities within the same range. However, for arrays with four or five GusA monomers RFU values were slightly decreased.

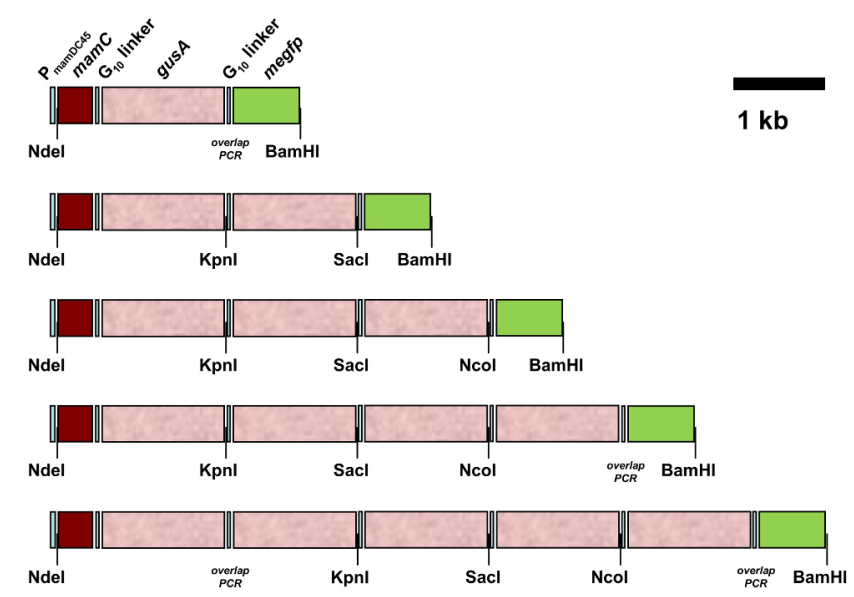

Figure S5. Genetic organization of $\operatorname{mamC}-(g u s A)_{1-5-m e g f p}$ expression cassettes, indicating fragments and restriction sites used for multi-fragment ligation approaches. The resulting fusion constructs were subsequently cloned into the NdeI / BamHI restriction sites of pFM2, thus creating expression cassettes under control of the optimized constitutive $\mathrm{P}_{\text {mamDC45 }}$ promotor and the optimized ribosome binding site (oRBS) (Borg et al. 2014). 
Table S1. Kinetic constants after several freeze / thaw cycles. Isolated MamC-GusA-mEGFP magnetosomes were subjected to GusA activity assays after the indicated number of freeze / thaw steps, and $\mathrm{K}_{\mathrm{M}}$ and $\mathrm{V}_{\max }$ values were calculated.

\begin{tabular}{lcc}
\hline Number of freeze / thaw cycles & $\begin{array}{c}\mathrm{K}_{\mathrm{M}} \\
{[\mathrm{mM}]}\end{array}$ & $\begin{array}{c}\mathrm{V}_{\max } \\
{\left[\mu \mathrm{mol} \mathrm{L}^{-1} \mathrm{~min}^{-1}\right]}\end{array}$ \\
\hline 0 & 0.17 & 2.61 \\
1 & 0.37 & 2.24 \\
3 & 0.56 & 1.55 \\
5 & 0.94 & 0.74 \\
10 & 1.71 & 0.01 \\
\hline
\end{tabular}

Table S2. Strains used in this study.

\begin{tabular}{|c|c|c|}
\hline Strain & Description & Source or reference \\
\hline \multicolumn{3}{|l|}{ Escherichia coli } \\
\hline $\mathrm{DH} 5 \mathrm{a}$ & $\begin{array}{l}\mathrm{F}^{-} \text {supE44 } \Delta \text { lacU169 (Ф80 } \\
\text { lacZDM15) hsdR17 recA1 endA1 } \\
\text { gyrA96 thi-1 relA1 }\end{array}$ & Invitrogen \\
\hline WM3064 & $\begin{array}{l}\text { thrB1004 pro thi rpsL hsdS } \\
\text { lacZ } \triangle 15 \text { RP } 4-1360 \\
\Delta(\operatorname{araBAD}) 567 \\
\Delta \text { dapA1341::[erm pir] }\end{array}$ & Metcalf, unpublished \\
\hline \multicolumn{3}{|l|}{ Magnetospirillum gryphiswaldense } \\
\hline M. gryphiswaldense MSR-1 R3/S1 & $\begin{array}{l}\text { Rif }^{R}, \mathrm{Sm}^{\mathrm{R}} \text { spontaneous } \\
\text { mutant, lab strain }\end{array}$ & Schultheiss and Schüler 2003 \\
\hline M. gryphiswaldense $\Delta m a m C$ & $\Delta m a m C$ & Scheffel et al. 2008 \\
\hline M. gryphiswaldense MSR-1 FM1 & $\begin{array}{l}\mathrm{R} 3 / \mathrm{S} 1, \mathrm{Km}^{\mathrm{R}} \text {, transposon mutant } \\
\text { with inserted mamC-gusA from }\end{array}$ & this study \\
\hline M. gryphiswaldense MSR-1 FM2 & $\begin{array}{l}\mathrm{P}_{\text {mamDC45 }} \\
\mathrm{R} 3 / \mathrm{S} 1, \Delta \text { mam } C, \mathrm{Km}^{\mathrm{R}} \text {, transposon } \\
\text { mutant with inserted mamC-gus } A \\
\text { from } \mathrm{P}_{\text {man }} \text { m }\end{array}$ & this study \\
\hline M. gryphiswaldense MSR-1 FM3 & $\begin{array}{l}\mathrm{R} 3 / \mathrm{S} 1, \mathrm{Km}^{\mathrm{R}} \text {, transposon mutant } \\
\text { with inserted mamC-gusA-megfp } \\
\text { from } \mathrm{P}_{\text {mamDC45 }}\end{array}$ & this study \\
\hline M. gryphiswaldense MSR-1 FM4 & $\begin{array}{l}\mathrm{R} 3 / \mathrm{S} 1 \Delta \text { mam } C, \mathrm{Km}^{\mathrm{R}} \text {, transposon } \\
\text { mutant with inserted mamC-gusA- } \\
\text { megfp from } \mathrm{P}_{\text {mamDC } 45}\end{array}$ & this study \\
\hline M. gryphiswaldense MSR-1 IK-1 & $\mathrm{R} 3 / \mathrm{S} 1 \Delta r e c A$ & Kolinko et al. 2011 \\
\hline M. gryphiswaldense MSR-1 FM5 & $\begin{array}{l}\mathrm{R} 3 / \mathrm{S} 1 \Delta r e c A, \mathrm{Km}^{\mathrm{R}} \text {, transposon } \\
\text { mutant with inserted mamC- } \\
(\text { gus } A)_{2} \text {-megfp from } \mathrm{P}_{\text {mamDC45 }}\end{array}$ & this study \\
\hline M. gryphiswaldense MSR-1 FM6 & $\begin{array}{l}\mathrm{R} 3 / \mathrm{S} 1 \Delta r e c A, \mathrm{Km}^{\mathrm{R}} \text {, transposon } \\
\text { mutant with inserted mamC- } \\
(\text { gus })_{3} \text {-megfp from } \mathrm{P}_{\text {mamDC45 }}\end{array}$ & this study \\
\hline M. gryphiswaldense MSR-1 FM7 & $\begin{array}{l}\mathrm{R} 3 / \mathrm{S} 1 \Delta r e c A, \mathrm{Km}^{R} \text {, transposon } \\
\text { mutant with inserted mamC- }\end{array}$ & this study \\
\hline M. gryphiswaldense MSR-1 FM8 & $\begin{array}{l}\mathrm{R} 3 / \mathrm{S} 1 \Delta r e c A, \mathrm{Km}^{\mathrm{R}} \text {, transposon } \\
\text { mutant with inserted mamC- } \\
\text { (gusA) })_{5} \text {-megfp from } \mathrm{P}_{\text {mamDC45 }}\end{array}$ & this study \\
\hline M. gryphiswaldense SB8 & $\begin{array}{l}\mathrm{R} 3 / \mathrm{S} 1, \mathrm{Km}^{\mathrm{R}} \text {, transposon mutant } \\
\text { with inserted gus } A \text { from } \mathrm{P}_{\text {tet }}\end{array}$ & Borg et al. 2014 \\
\hline
\end{tabular}


Table S3. Plasmids used in this study.

\begin{tabular}{|c|c|c|}
\hline Plasmid name & Description & Source or reference \\
\hline pBAM1 & $\mathrm{Km}^{\mathrm{R}}, \mathrm{Amp}^{\mathrm{R}}$, oriR6K, $\operatorname{tnpA}$ & $\begin{array}{l}\text { Martinez-Garcia et al. } \\
2011\end{array}$ \\
\hline pJH1 & $\begin{array}{l}\text { pBAM1 with } \mathrm{P}_{\text {mamDc45, }} \text { mamC-megfp, } \\
\mathrm{Km}^{\mathrm{R}}, \mathrm{Amp}^{\mathrm{R}}\end{array}$ & Borg et al. 2014 \\
\hline pSB8 & $\begin{array}{l}\text { pBAM1 with } \mathrm{P}_{\text {tet }} \text {, gusA, } \mathrm{P}_{\mathrm{Neo}}-\mathrm{TetR}, \mathrm{Km}^{\mathrm{R}} \text {, } \\
\text { Amp }^{\mathrm{R}}\end{array}$ & Borg et al. 2014 \\
\hline pSB9 & $\begin{array}{l}\text { pBAM1 with } P_{\text {mamDC45, }} \text { mamC-gusA, } \\
\mathrm{Km}^{\mathrm{R}}, \mathrm{Amp}^{\mathrm{R}}\end{array}$ & Borg, unpublished \\
\hline pFM2 & $\begin{array}{l}\text { pBAM1 with } \mathrm{P}_{\text {mamDC45 }}, \text { mamC-gusA- } \\
\text { megfp, } \mathrm{Km}^{\mathrm{R}}, \mathrm{Amp}^{\mathrm{R}}\end{array}$ & this study \\
\hline pFM3 & $\begin{array}{l}\left.\text { pBAM1 with } \mathrm{P}_{\text {mamDC45 }}, \text { mamC-(gusA }\right)_{2^{-}} \\
\text {megfp, } \mathrm{Km}^{\mathrm{R}}, \mathrm{Amp}^{\mathrm{R}}\end{array}$ & this study \\
\hline pFM4 & $\begin{array}{l}\left.\text { pBAM1 with } \mathrm{P}_{\text {mamDC45 }}, \text { mamC-(gusA }\right)_{3^{-}} \\
\text {megfp, } \mathrm{Km}^{\mathrm{R}}, \mathrm{Amp}^{\mathrm{R}}\end{array}$ & this study \\
\hline pFM5 & $\begin{array}{l}\left.\text { pBAM1 with } \mathrm{P}_{\text {mamDC45 }}, \text { mamC-(gusA }\right)_{4}- \\
\text { megfp, } \mathrm{Km}^{\mathrm{R}}, \mathrm{Amp}^{\mathrm{R}}\end{array}$ & this study \\
\hline pFM6 & $\begin{array}{l}\left.\text { pBAM1 with } \mathrm{P}_{\text {mamDC45 }}, \text { mamC-(gusA) }\right)_{5^{-}} \\
\text {megfp, } \mathrm{Km}^{\mathrm{R}}, \mathrm{Amp}^{\mathrm{R}}\end{array}$ & this study \\
\hline
\end{tabular}

Table S4. Primers and oligonucleotides used in this study. Restriction sites are indicated in bold.

\begin{tabular}{|c|c|c|}
\hline Primer name & Sequence $\left(5^{\prime}-3^{\prime}\right)$ & Restriction site \\
\hline mamC Ndel fwd & GATCAG CATATG AGCTTTCAACTTGCGCCGTACTTG & Ndel \\
\hline gusA Kpnl rev & GAGAT GGTACC TTGTTTGCCTCCCTGCTGCGGTTTTTC & Kpnl \\
\hline gusA Kpnl fwd & $\begin{array}{l}\text { CATCTT GGTACC GGAGGCGGAGGCGGTGGCGGAGGTGGCGGAAT } \\
\text { CGATATGTTACGTCCTGTAGAAACCCCAAC }\end{array}$ & Kpnl \\
\hline gusA Sacl rev & GAGATTAA GAGCTC TTGTTTGCCTCCCTGCTGCGGTTTTTC & Sacl \\
\hline gusA Sacl Clal fwd & $\begin{array}{l}\text { CTATTA GAGCTC GGAGGCGGAGGCGGTGGCGGAGGTGGCGGA } \\
\text { ATCGAT }\end{array}$ & Sacl / Clal \\
\hline gusA Ncol rev & GATGCAT CCATGG CCTTGTTTGCCTCCCTGCTGCGG & Ncol \\
\hline gusA-linker rev & $\begin{array}{l}\text { ATCGAT TCCGCCACCTCCGCCACCGCCTCCGCCTCCTTGTTTGCCT } \\
\text { CCCTGCTGCGGTTTTTC }\end{array}$ & Ncol \\
\hline linker-gusA fwd & $\begin{array}{l}\text { GGAGGCGGAGGCGGTGGCGGAGGTGGCGGA ATCGAT ATGTTACG } \\
\text { TCCTGTAGAAACCCCAACCCGTGAAATCAAAAAAC }\end{array}$ & Ncol \\
\hline linker-GFP fwd & GGAGGCGGAGGCGGTGGCGGAGGTGGCGGA ATCGAT ATG & Ncol \\
\hline linker GFP fwd Sacl & $\begin{array}{l}\text { CTAGAT GAGCTC GGAGGCGGAGGCGGTGGCGGAGGTGGCGGAAT } \\
\text { CGATATG }\end{array}$ & Sacl \\
\hline $\begin{array}{l}\text { GFP rev BamHI } \\
\text { linker2-gusA fwd }\end{array}$ & $\begin{array}{l}\text { GACCC GGATCC TCACTTATACAGCTCGTCCATGCCCAG } \\
\text { GGTGGAGGCGGTGGCGGAGGTGGCGGAGGCATGTTACGTCCTGTA } \\
\text { GAAACCCCAACCCGTGAAATCAAAAAAC }\end{array}$ & BamHI \\
\hline gusA-linker2 rev & GCCTCCGCCACCTCCGCCACCGCCTCCACCTTGTTTGCCTC & \\
\hline gusA rev BamHI & GGACCC GGATCC TCATTGTTTGCCTC & BamHI \\
\hline
\end{tabular}




\section{References Supporting Information}

1. M. Myronovskyi, E. Welle, V. Fedorenko, A. Luzhetskyy, Appl. Environ. Microbiol. 2011, $77,5370$.

2. S. Borg, J. Hofmann, A. Pollithy, C. Lang, D. Schüler, Appl. Environ. Microbiol. 2014, 80, 2609.

3. D. Schultheiss, D. Schüler, Arch. Microbiol. 2003, 179, 89.

4. A. Scheffel, A. Gärdes, K. Grünberg, G. Wanner, D. Schüler, J. Bacteriol. 2008, 190, 377.

5. I. Kolinko, C. Jogler, E. Katzmann, D. Schüler, J. Bacteriol. 2011, 193, 5328.

6. E. Martinez-Garcia, B. Calles, M. Arevalo-Rodriguez, V. de Lorenzo V., Bmc Microbiol. 2011, 11,38 . 